\title{
The Diversity of Social Systems \\ of Innovation and Production \\ during the 1990s
}

$N^{\circ}$ 2001-15

\author{
Bruno AMABLE \\ Pascal PETIT
}

Consulter le WEB : http://www.cepremap.cnrs.fr

"Bruno Amable (Université PARIS X/Nanterre, CEPREMAP, MODEM) 48 boulevard Jourdan 75014 Paris bruno.amable@cepremap.cnrs.fr

*Pascal Petit (CNRS-CEPREMAP) 142 rue du Chevaleret 75013 Paris, pascal.petit@cepremap.cnrs.fr 


\section{The Diversity of Social Systems of Innovation and Production during the 1990s*}

\section{Summary}

The notion of Social System of Innovation and Production (SSIP) refers to an approach that tries to incorporate institutional elements into the economic analysis of technological change and to study the impact of these elements on long-term economic performance. The complementarities that exist between institutions are fully taken into account, leading to characterize broad configurations of institutions more comprehensively than usually retained in approaches in terms of national systems of innovation. Once the diversity of these patterns and of their influence on economic performance is assessed, the paper attempts to track down the transformations that are likely to have affected these SSIPs over the 90s. Various trends of convergence and divergence among the groups of countries distinguished are considered showing to what extent SSIPs will remained rather diverse, a diversity that European and national innovation policies should clearly take into account in order to be efficient.

\section{La diversité des systèmes sociaux d'innovation et de production au cours des années 1990}

\section{Résumé}

La notion de système social d'innovation et de production renvoie à une approche qui cherche à incorporer des éléments institutionnels dans une analyse du changement technique et à étudier l'impact de ces éléments sur les performances économiques à long terme. Les complémentarités qui existent entre institutions sont pleinement prisent en compte, ce qui conduit à caractériser des configurations d'institutions de façon beaucoup plus large qu'il n'est fait habituellement dans les approches en terme de systèmes nationaux d'innovation. Une fois explicité la diversité de ces modèles et de leur influence sur les performances économiques, le présent document de travail s'attache à récupérer les transformations susceptibles d'avoir affecté les SSIP dans les années 90 . Diverses tendances à la convergence ou à la divergence entre les différentes familles de pays considérés sont ensuite prises en compte pour voir jusqu'à tel point la diversité des SSIP se maintiendrait dans le futur, une diversité que les politiques d'innovations, nationales où à l'échelle de l'Europe, devrait clairement prendre en compte pour être efficaces.

MOTS CLES : Changement technique, système d'innovation, croissance à long terme, analyses économiques, complémentarités institutionnelles.

KEY WORDS: Technical change, innovation systems, long term growth, comparative economics, institutional complementarity.

CLASSIFICATION JEL : O1, O2, D2, E2

\footnotetext{
${ }^{*}$ The drafting of this paper prepared for the Second Conference of the Centre Saint-Gobain pour la Recherche en Economie (Paris La Défense, June 2001) was facilitated by discussions with Yann Cadiou, Ekkehard Ernst, Donatella Gatti, Stefano Palombarini, Xavier Ragot, Bruno Théret and JeanPhilippe Touffut. The authors would like to thank them without associating them with any deficiencies the paper may have. It draws for a part of its empirical investigations on a work done in collaboration by the authors within an EC TSER CDIS project which can be further documented in Amable, Cadiou and Petit (2000).
} 


\section{The Diversity of Social Systems of Innovation and Production during the 1990s}

\section{Introduction}

The concept of an "innovation system" (IS) is a reference to the various attempts that have been made to incorporate institutional elements into the economic analysis of technical change, and to study the impact of these elements on long-term economic performance. ${ }^{1}$ Many research projects have started out with the same premise, i.e., that it is necessary to get away from a conception in which innovation is viewed as a simple process of individual decision-making that is enacted independently from the institutional environment. ${ }^{2}$ Innovation necessarily implies interactions between actors (firms, researchers, universities, laboratories, etc.) and their environment. Moreover, it is wrong to think that such environments are comprised of nothing more than market price(s), albeit contingent. In reality, they consist of a whole set of rules, forms of organisation, and institutions. The differences in "technological styles" that can be observed at the territorial level (usually a national territory, although this can sometimes cover a region or any wider grouping of countries), or even at the sectorial level, stem from the differences in the institutional configurations that are specific to each of these territories. The expression "technological style" is intentionally vague, given the diversity of the characteristic features of the technical change that is being associated with these institutional particularities: rate of technical change; type of innovation (i.e., radical or incremental); a sectorial specialisation that varies as a function of the level of technological intensity or even the long-term growth rate.

This being the case, which types of institutions should be integrated into innovation systems studies ? IS research derives from the economics of technical change, and a large proportion of the work that has been carried out in this field has therefore concentrated on institutions that are directly involved in scientific or in technical activities. ${ }^{3}$ This includes scientific systems, research laboratories, scientific institutions of technology, and possibly universities and institutes of higher education - as well as the relationships that such institutions entertain with the corporate sector. However, this minimalist conception of IS is not the only possibility. Other approaches will include a wider range of institutions in their framework, encompassing a few institutions that get involved on a more or less ad hoc basis. After all, if innovation is an accumulation of knowledge, the training system as a whole should be seen as an important constituent of an IS. Moreover, the financial system necessarily plays a role in IS if firms are financially constrained in terms of the investments that they are able to make in innovation. As such, an Innovation System's borders, in the widest sense of the term, are moveable.

This extended conception of IS fits in with a literature that does not specifically take the economics of technical change as its starting point, but which focuses instead on the varying institutional structures that can be found in the developed economies. The numerous studies that have been made of "varieties of

\footnotetext{
1 On the role of institutions in economic development, see North [1990]. For an analysis of the importance of institutions in innovation systems, see Amable [2000].

2 See Freeman [1995], Smith [1998].

3 See inter alia Freeman [1987].
} 
capitalism"4 have all followed a comparative approach when dealing with contemporary developed economies. These studies have focused on the way in which those societies that feature a wide range of institutional arrangements have been able to nurture and reproduce this diversity - despite the growing integration of the world's economies. Another aspect of this diversity is that national institutional structures cause variations in the different economies' ability to compete in a given type of production or sector of activity. In a certain sense, institutional diversity leads to comparative institutional advantages. ${ }^{5}$ Conversely, the economic (and technological or even scientific) specialisation of the developed economies has caused people to take a closer look at the structures that characterise the institutions which are specific to a given society.

It could even be said that these other studies are dealing with the same topic as IS-related research projects are - without emphasising the technological determinism that is hallmark of this latter corpus. The relationship between the two bodies of literature can be seen from two perspectives:

- IS's, in their restrictive (minimalist) denotation, constitute a subgroup of the total economy, and IS-related literature is therefore a sectorial application of research into the different varieties of capitalism.

- IS's, in their extended denotation, constitute another way of apprehending the differences between the various types of capitalism, insofar as they attribute a specific role to innovation and to the factors that drive competitiveness and longterm growth.

A "social systems of innovation and production" (SSIP) ${ }^{6}$ approach is an attempt to transcend these two points of view. Like studies that delve into varieties of capitalism, it constitutes an all-encompassing economic approach. As such, the institutions that are deemed relevant, and which are therefore integrated into SSIP analysis, transcend the scientific and technological fields alone. Nor does SSIP postulate that scientific and technological phenomena constitute the core of the appropriate theoretical framework - a view that one finds in the extended IS approaches (which define relevant institutional spheres by moving progressively outwards from a centre comprised of an IS in the minimalist sense of the term). However, an SSIP approach does attribute a specific role to innovation and to technique, not because it has fallen prey to the idea that all of an economy's institutions are subject to technological determinism, but because technological competitiveness (and at a more general level, one's insertion in the international division of labour) is a good indicator of all of the mutual influences between institutional structures and macroeconomic trends. For the contemporary period at least, innovation is a useful gateway, inasmuch as it can provide access to an entire economic system. Moreover, by including institutions above and beyond those that are solely involved in scientific and technological endeavours, the SSIP analysis shows that it is trying to account for, and study, sources of innovation that may lie outside of this minimalist inner circle.

The SSIP approach, like the varieties of capitalism and the IS approaches, must cope with issues such as the potential superiority of a given economic model, and the possibility that economies will become more or less diverse over time. At the same time, evolutionist arguments hold that competition between economies will lead to the birth of economies in which the least efficient institutional structures will be transformed, adopting the traits of whichever economies show the greatest efficiency. The contention is nothing new, yet it has continued to crop up from time to time. Its current version revolves around two phenomena : globalisation; and the new economy.

\footnotetext{
${ }_{5}^{4}$ See inter alia Kitschelt et al. [1999], Whitley [2000] etc. for recent contributions on this subject.

5 Soskice [1999].

${ }^{6}$ Amable, Barré \& Boyer [1997]
} 
One relatively widespread thesis is basically the following: (i) the "new economy" defines a new long-term growth trajectory ${ }^{7}$; (ii) associated with this trajectory are an array of institutions that are capable of stimulating the technical change and structural changes which are needed to launch the technological trajectory that the new economy has defined ; (iii) lastly, as would seem to be indicated on one hand by the United States' advance in the new IT-related technologies, and by its superior macro-economic performances during the 1990s on the other, to be successful one has to adopt American institutional characteristics.. The example of the United Kingdom allegedly represents the confirmation of this thesis, as well as the proof that it is possible to overcome Euro-sclerosis. In sum, changes in modern capitalism are supposedly leading the developed countries towards an "Anglo-Saxon" model, replete with deregulated financial markets, "flexible" labour markets, technologically dynamic newly created firms, greater competition in the product markets, etc. All in all, a situation that is relatively distant from the trajectory followed by the Continental European economies in the aftermath of the Second World War.

The purpose of the present article is to subject SSIP analysis to these factors. This requires revisiting the theoretical foundations underlying the SSIPs' diversity the objective of the present article's first section. We will then study those transformations that are most likely to have affected the way in which the various SSIP's developed over the course of the 1990s. A third section will focus on the developed economies' comparative performances over the past decade, insofar as this relates to the "new economy". Having observed that it is difficult use a single model to account for comparative changes in the various developed economies, we will use empirical analyses to delve further into the SSIPs' diversity during the 1990s. We will show what sorts of developments have affected the SSIPs that were identified in Amable, Barré and Boyer [1997], and how to best assess the convergences and divergences between the various types of capitalism. Our conclusion will offer several hypotheses regarding future trends in Europe, and particularly in France.

\section{The institutions' diversity and complementarity}

\section{1.a. Globalisation and institutional diversity}

It has become customary to analyse economies' contemporary transformations through the use of two analytical matrices that are not entirely unrelated. The first matrix is "globalisation", or more simply, economies' recent internationalisation trends. ${ }^{8}$ Such arguments could be rapidly summarised as follows: we are witnessing an intensification of international economic relationships thanks to the deregulation of commercial trade, which increases competition on the product markets; and due to financial liberalisation, which facilitates investment flows and tends to generalise the principles of market-based finance worldwide. Amongst other effects, this latter trend has lead to a greater need for investment liquidity; to new principles of corporate governance (in which the financial incentivisation of executives plays a greater role); and to an ex post control of businesses that are under the threat of being taken over. Capital has become increasingly mobile, leading to an extension of the sphere within which private companies can act - and firms have centred their strategies around the world market rather than the national

\footnotetext{
${ }^{7}$ Whether this involves a new technological paradigm or a new positive phase in a long-term growth cycle.

8 There is of course a great deal of literature on globalisation ; for a summary of the main points, see inter alia Jacquet \& Sachwald [2000].
} 
or "regional" ones. This implies a weaker bargaining position for labour, with changes in the nature of the employment relationship ${ }^{9}$ having lead to increased differentiation in employee status, an individualisation of remuneration, etc. The main consequence of this trend is increased competition between national spaces that define their competitiveness in terms of their "factor endowment" - infrastructure, but also (and above all) the economic institutions that are present in these territories. Also include are the regulations that affect the functioning of the factor markets (labour and capital), the efficiency of the educational and training systems, etc. The implications of this increased competition can be understood intuitively; and it is strongly recommended that countries experiencing economic difficulties align themselves with current best practices if they do not wish to fall behind in terms of their international competitiveness. But how can one recognise these best practices ? From an empirical point of view, they are necessarily those practices that have been adopted by the countries who have achieved the best economic performances. Alternatively, from a theoretical point of view, the best practices are the ones that bring markets closer to a state of perfection. Luckily enough, the developed countries' comparative performances over the past decade would seem to indicate the coincidence of these two criteria ${ }^{10}$. The most dynamic economies are also the ones that have adopted the practices (or attitudes) that most closely approximate this market-based ideal. The other economies (Japan, Europe) are supposedly suffering, on the other hand, from over-regulation, high taxes, barriers to competition, etc.

The second analytical matrix is more technological in nature, and revolves around the composite notion of a "new economy" ${ }^{11}$ - this being a concept that certain observers use to signify a relatively vast array of transformations. The effect of this intensification of technical progress has been to raise productivity gains wherever they had been stagnating (in the United States). Technical progress has been concentrated in certain technologies and sectors, as suggested by neoSchumpeterian theories concerning long-term cycles ${ }^{12}$. These are the sectors that are involved in innovation and communication technologies (ICT), with innovation and technological dynamism playing a greater role in the definition of competitiveness, both for firms and for countries as a whole. Hence the importance of staying on the bandwagon of ICT-related transformations. More than ever, technological dynamism is seen as being dependent on small innovative firms (the start-ups). Moreover, in order to develop, these firms need a favourable environment (flexible labour, the ease with which a company can be created or disbanded, the availability of qualified personnel, of venture capital, etc.). Market-based financing is more efficient than bank financing in supporting a technological trajectory that revolves around these kinds of firms. This is not an exhaustive list, ${ }^{13}$ but it is sufficient to elucidate the major orientations of the new economy.

When such analytical matrices are used to apprehend the transformations which the developed economies have been experiencing, the suggestion is that even if current orientations are not leading to a disappearance of specific national markets, they are at the very least causing a significant diminution in the contemporary economies' diversity. Given that these trends are being forced upon countries all across the world, any delay in adapting to these new conditions leads, in this view, to a handicap in competitiveness. This is a summary of the argument that all countries should be trying to adapt to globalisation. Moreover, even those who oppose this point of view usually agree that the new internationalisation modalities of the world's

\footnotetext{
${ }^{9}$ See Beffa, Boyer \& Touffut [1999] regarding the transformations of the employment relationship.

10 The commentaries were quite different when Made in America was first published.

${ }^{11}$ See OECD [2000], Artus [2001].

${ }^{12}$ See Freeman \& Soete [1997].

13 We could have also mentioned the disappearance of the inflation/unemployment cycle and/or conundrum, the diminished role of economic policy, etc.
} 
economies infer a more or less rapid convergence towards a single model - one that is based on deregulated market-based finance; on the primacy of shareholder value; on pension funds; on the dismantling of welfare systems; on the privatisation of public services; on the existence of an "underclass". What they question is whether this trend is desirable - but not the diagnosis itself.

There is also a more or less homogenous school of thought that focuses on the "diversity of capitalisms". This diversity is not seen as something that is accidental or temporary, but as the consequence of mechanisms that can be grouped under the generic title of "institutional complementarities". ${ }^{14}$ In this view, economies basically diverge in terms of the institutions that characterise them, depending on the particular aspect of the economy that is being studied. The labour market can be more or less regulated ; wage bargaining more or less centralised ; and the financial systems more or less reliant upon the banks, or else on the freedom that they give to the financial markets. In general, education is organised quite differently from one country to the next, with more or less close ties to industry; universities that are more less independent ; and a competition between private companies that is more or less intense. An initial approach would be to suppose that an optimal solution exists in each these areas, independently of the institutional configurations that are present in any of the other areas. The best institutional configuration for an economy is therefore the one that is closest to the sum total of these optimal local configurations. This conception is very probably the driver behind benchmarking efforts - and the basis of international comparisons such as those that have been carried out by the World Economic Forum (Davos) or more recently by Lehman Brothers. ${ }^{15}$ The purpose of such studies is usually to classify countries in terms of their competitiveness. Towards this end, a certain number of categories are defined, and countries are marked for their performance in a given category. An overall mark is then obtained by adding up the scores from each area. The best model is the one that is closest to the profile that has been defined as being the best local configuration. For information, read Edwards and Schanz's study [2001]. Their findings can be interpreted as follows : the ideal economy possesses Denmark's educational system ; Sweden's technology and employment policy: the competitive environment of Finland's high-tech sector; and the entrepreneurial environment, wage flexibility, (non)-protection of employment, fiscal system, competitive environment, economies of scale and productivity of the United States. It remains to be seen whether this mixture of American and Scandinavian institutions would be viable. The answer is yes if one believes that it is possible to play "institutional lego". If one adapts a view that encompasses inter-institutional interactions, nothing is less certain.

Institutional complementarity does not consider institutions in isolation but as a whole. The idea is that each institutional arrangement's existence or functioning within a given area is enhanced by the institutional arrangements that are in effect in other areas. If certain conditions are met, negotiations between social partners in a given labour market can create the sort of stable compromises that could help the workforce to receive a high level of training. In addition, physical investment is facilitated by the existence of close relationships between banks and firms. In this scenario, the existence of durable relationships, and of proximity between banks and firms, enhances the implementation of long-term investment projects, and in return this facilitates the establishment of stable compromises in the labour market. Conversely, a flexible labour market, one that facilitates employee mobility, is seen here as complementing a financial system that facilitates the reversibility of commitments and the liquidation of investments. This means that the range of

\footnotetext{
${ }^{14}$ See Aoki [2000], [2001], Amable [2000], Amable, Ernst \& Palombarini [2000], Soskice [1999], Ernst [2001], Gatti [2000], Freeman [2000], Whitley [2000]

${ }^{15}$ Edwards \& Schanz [2001].
} 
potential complementarities can be extended to cover such areas as innovation, professional training systems, etc. In conditions such as these, attempts to reengineer institutions have no real meaning. By modifying institutions locally, one runs a risk of weakening the coherency of the institutional structure as a whole - and of diminishing economic performances instead of improving then.

An institutional complementarity approach could therefore see the survival of different models of capitalism as a reflection of interactions between institutions. It is also a complementary way to explain institutional inertia, sometimes used as an alternative to arguments that focus on the fixed costs or increasing returns. In fact, one explanation for the survival of institutions that can appear to be inefficient (at a local level) draws a parallel between the increasing returns to adoption and the consequences of these increasing returns (i.e., being forced to follow a given technological trajectory ${ }^{16}$ ). Just as increasing returns to adoption can explain why certain events lead an economy down a given technological path (one which it will find difficult, or even impossible, to leave), history also explains why institutions that were adopted for once good reasons survive even after these reasons have disappeared. As such, institutions' dependency on historical factors ${ }^{17}$ leads to a certain amount of inertia - and to the survival of certain (locally) inefficient institutions, despite this very inefficiency.

As regards institutional complementarities, certain institutions that would appear to be inefficient at a local level can in fact play a crucial role in determining the overall coherency of a country's institutional structure. Employment protection policies can hamper employment, as well as other variables such as profitability (under certain macro-economic conditions, i.e., where adverse demand shock has taken place). However, this can be justified by the role that these policies play as the guarantor of an employer's long term commitments to an employment relationship with an employee - and by their role in providing an incentive for investments that specifically augment the value of this relationship. It is very possible that the price to pay in flexibility terms is lower than the gains that can be achieved as a result of the increased value of the employment relationship - something that can become visible over the long run.

Note that the existence of complementarities has been reflected in the economic policy recommendations that major international organisations such as the OECD have been making. Taking one area in which recent studies have been carried out (the interaction between competition in the product markets and imperfections in the labour market ${ }^{11}$ ), economic policy recommendations have gone far beyond simple correction of each market's imperfections. More specifically, the expected benefits of correcting these imperfections are greater than they would be if the product and labour markets were considered separately. By allowing for increased competition on the product markets, the expectation is that additional gains are there to be gained once the labour markets are deregulated. Liberalising one of these markets enhances the benefits that are to be had from deregulating the other. As a result, the deregulation of the labour market is supposed to be accompanied by an intensification of competition in the product markets, with the two types of reform being seen as complementary ${ }^{19} 20$.

\footnotetext{
${ }^{16}$ See Arthur [1994]

17 David [1994]

${ }^{18}$ Nicoletti et.al [2000]

${ }^{19}$ On the policies' complementarity see Coe \& Snower [1997], Orszag \& Snower [1998]

20 See Amable \& Gatti [2000], [2001] concerning the incorporation of the different complementarities, and for less orthodox types of recommendations.
} 
However, integrating complementarities into policy is not the same thing as moving towards institutional diversity. This is because of the ubiquity of the references that are being made to a single, optimal institutional configuration - in short, to the idea that increasing competition everywhere is the best way to overcome market imperfections. It remains that contributions which basically relate to the study of the varieties of capitalism or to the existence of institutional complementarities stress that diversity is the logical outcome of an integration of the institutions' functioning (and influence on economic decision-making) into the analysis.

\section{1.b. Diverse types of capitalism}

Numerous studies have focused on the different kinds of capitalism that exist, or on the specificity of each national model ${ }^{21}$. A theoretical analysis and an exercise in international comparisons, Amable et. al., [1997) highlighted four main types of "capitalism" or Social Systems of Innovation and Production (SSIP): market-based SSIP's (best embodied by the United States, Great Britain, Australia and Canada) ; a social-democratic SSIP (best embodied by the Scandinavian countries) ; a mesocorporatist SSIP (seemingly tailor-made for Japan); and a "European" SSIP (best embodied by France, Germany, Italy and the Netherlands). This classification diverges from other authors' findings. Indeed, some studies tend to emphasise national specificities, considering that each country constitutes its own category. Others base their understanding of diversity on two polar extremes (i.e., the United States and Germany) and classify countries according to their differences, or similarities, to these extreme cases. In Amable et al., SSIP's are seen as ideal-types, instead of as more or less stylised descriptions of the main characteristics of a given country $^{22}$. This obviates the need to come up with an exact identikit creating a match between a given SSIP and the group of countries that best embodies it.

Identifying SSIP's involves both theoretical elements (i.e., an expression of the institutional complementarities that are at work in the countries comprising these SSIP's) and empirical elements (through the processing of a large base of statistical indicators covering these 12 countries - the data being analysed in such a way as to identify country typologies). Devising a theoretical underpinning for the typologies derived from this empirical analysis is not necessarily the same thing as "naming" the model or SSIP that has been discovered. It is not always possible to come up with a name that can correctly summarise the SSIP. Take for example the "market-oriented" SSIP that is linked to the Anglo-Saxon countries. The descriptor "market-oriented" does not at first glance appear to cause any conflicts with traditional writings in this field $^{23}$. It is an indication that the basic principle underlying the SSIP in question is a "market" logic, characterised by the significance of price-driven regulation, by competition between the agents, by flexible arrangements, by speedy reactions to price signals, etc. Here the term "basic principle" means for example that a market logic applies to all of the sub-systems of a market-oriented SSIP, via a kind of isomorphism. To a large extent, this is true - but there is much more to be said.

\footnotetext{
${ }^{21}$ Some of these studies have become renowned even outside of academic circles (Albert, 1991].

${ }^{22}$ On problems of methodology in international comparisons, see Théret [1997]. Here we are following a compromise approach (Théret, 1997: pp.178-179] between increased generalisation ( a formalisation that is based on empirical characteristics) and a diminished contextualisation of universal categories (which incorporates into the indicators both contextual and universal elements). Note that Théret [1997] has also put together a country-by-country classification that is very similar to the SSIP approach, based on comparisons of levels of social protection. On this topic, also see Théret [2001].

${ }^{23}$ The United States and the United Kingdom belong to a neo-liberal market-oriented configuration, according to Soskice [1999], who contrasts them with a co-ordinated market-oriented economy such as Germany. This is similar to the Anglo-Saxon or American capitalism notion that had already been identified by other authors (notably by Albert, 1991].
} 
In an institutional complementarity concept logic, varieties of capitalism or different SSIP's stem from complementarities between the various types of institutions. ${ }^{24}$ This can be seen by analysing the different areas where such institutions are relevant. Consider for example an economy with three areas $(1,2, \&$ 3 ) and two possible types of institutions in each area (I \& I'). The institutional complementarities theory will state for example that only two configurations are possible (I1, I2 \& I3, on one hand, and I' 1 , I'2 \& I'3, on the other). This is because these configurations are stable, or perform better. This argument eliminates the six other possible types of institutional combinations, that is, mixtures of Type I institutions and Type l' institutions. Institutional complementarities can tie the institutions to one another on a two-by-two basis, as shown in the figure below. In this case, the two varieties of capitalism are characterised by the complementarities (C1, C2 \& C3) and (C'1, C'2 \& C'3). If one model is called Model $M$ and the other model M', with $\mathrm{M}$ and $\mathrm{M}$ ' having a specific meaning (such as a "market" logic or a "State-run" economy, for example), it appears possible to find M within C1, C2 \& C3, and M' within C'1, C'2 \& C'3. However, nothing indicates a priori that $(C 1, C 2, C 3)$ or ( $\left.C^{\prime} 1, C^{\prime} 2, C^{\prime} 3\right)$ can be reduced to a single principle.

All of this becomes easier if complementarities can be found between a given position and all of the others. If for example the complementarity $C 1\left(C^{\prime} 1\right)$ turns out to be indispensable to the existence of other complementarities, it can then be considered that one is in the presence of a $C_{1}\left(C^{\prime} 1\right)$ model. Even if $C_{1}\left(^{\prime} C^{\prime} 1\right)$ is not going to be found between all of the institutions in the model, it remains that the complementarities which derive from it are there. This institutional hierarchy provides signals as to the directions towards which the model may possibly be developing, an aspect that we will explore further below.

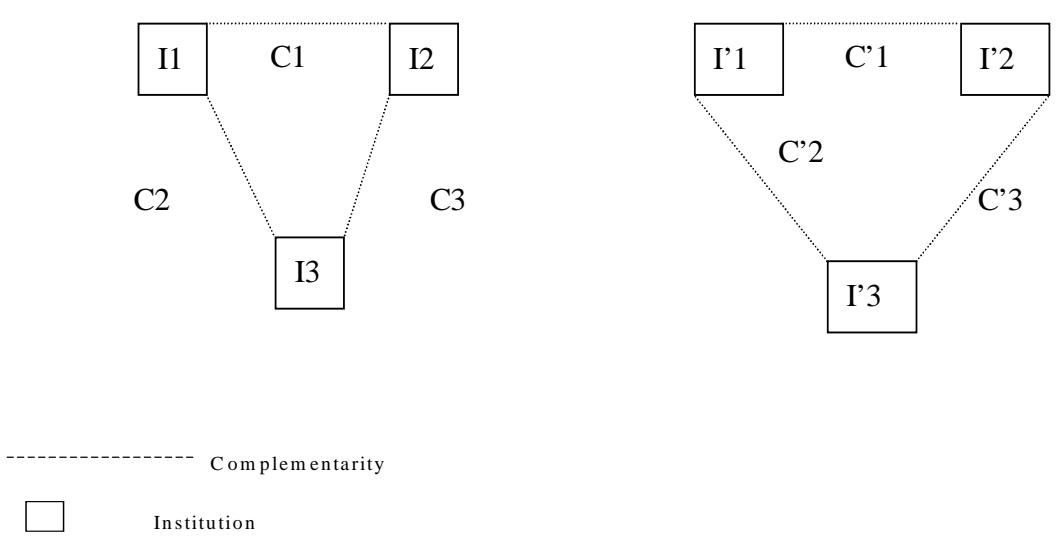

With the exception of an institutional hierarchy that has already been clearly identified, it is generally difficult to see a model as nothing more than the expression of a single logic - especially when this logic has to be expressed with simplicity. Several interrelated logics are involved in the coherency of any given model. These logics are sometimes local inasmuch as the mechanisms involved only affect a limited number of institutions and areas. This does not necessarily infer the existence of a single unifying principle, active throughout the economic model in question. However, a certain overall coherency does exist, related to the behaviour that agents display. The various fields may well be distinct from one another, but agents do in fact belong to several different fields, and their behaviour is determined by a system of beliefs and shared values that can help to describe a particular model.

\footnotetext{
${ }^{24}$ For more on complementarity, see also Amable and Petit [1999].
} 
Reverting to the example of the market-based model ${ }^{25}$ (called the AngloSaxon model by many authors, sometimes the neo-liberal market-oriented economies ${ }^{26}$ ), it could be said that this logic influences all of the institutional arrangements that are found in this model. As a result, even if this market logic is not found in all of the economy's subsystems, it nevertheless conditions the local logics found therein. Describing one and the same model as an "Anglo-Saxon " one might be less risky than using the term "market-oriented". One can always contest the preeminence of market mechanisms in these economies, but it is difficult to deny that these are the so-called Anglo-Saxon countries. The problem with this labelling is that it is not very explicit about whatever it is that the countries in this model share; and it does not express any economic theory for this model. It does however infer a number of things: the role of history, a common culture, etc. These inferences need to be rendered explicit and justified at a theoretical level - after all, "culture" is utilised as a last resort argument in many comparative studies. Lastly, note that it would have been possible to describe a market-oriented SSIP as an "Echelon" one, playing on the name of the information gathering system that has been instituted at the behest and under the direction of United States. This other label could open new perspectives with respect to the coherency of the model in question.

The fact that it is hard to find this coherency is a good illustration of the "European" or "State-run" SSIP. There is a good chance that more than just the one principle is at work, i.e. that several principles are operative, and that they are enacted locally. It is also manifest that the countries that best embody this SSIP are hybrid in nature: in certain respects Germany is close to the social-democratic SSIP, the Netherlands features certain traits of the market-oriented model, etc. The group of countries being considered here is probably the least homogeneous of all - and this is the SSIP that has been defined with the lowest degree of precision.

\section{What is new in the 1990s?}

Self-styled institutional complementarities approaches are sometimes criticised for being too static, and for not correctly explaining the changes that have been affecting the economies. After all, if economies are made up of complementarities that represent an amalgamation of specific institutional forms, no single element can be modified without the system as a whole being changed. Yet if this is so, how can we explain the diffusion of new practices (i.e., new management principles), something that constituted a readily observable empirical fact during the 1960 s and until the present? ${ }^{27}$ To answer this question, the changes have to be differentiated by category. Certain changes do not require any rethinking of institutional arrangements - to use Kogut's expression [2000], they are institutionally neutral. As such, they do not constitute a subverting of the institutional complementarities' stability. However, other practices can necessitate institutional changes and therefore ultimately destabilise the institutional architecture of a given model. However, the integration of institutional complementarities into an analysis does not mean that change is impossible. Static considerations and an emphasis on coherency and stability should only be seen as instances of institutional analysis, and not as a worldview.

If we want to speak of the permanency of a style of capitalism, the related institutional complementarities must be capable of preserving themselves in a

\footnotetext{
${ }^{25}$ As is the case with all of the economies that are considered to be market-oriented, it may appear inaccurate to apply the term "market-oriented" to just one SSIP. We could also speak of a "neo-liberal" model.

${ }^{26}$ Soskice [2000].

${ }^{27}$ See Kogut [2000] for a formulation of this type of criticism.
} 
dynamic manner. All economies undergo transformations under the influence of external factors - but also as a result of their own economic and institutional dynamics. Certain institutions can be modified, adapting to those transformations that are having an effect on all of the economies at a given moment in time, without damaging the model's stability. Localised or generalised hybridation can take place in the absence of any radical transformation. Having said that, hybridation is not the only transformation logic that exists - institutional innovation does not just involve recombining the same elements in a different way ${ }^{28}$. The principles underlying the institutional complementarities of a given system can lead to new forms that serve to preserve these principles. However, there are other types of transformations that do raise questions about all of these current institutional complementarities. This is because they affect those complementarities that are most essential to a model. In sum, not all institutional complementarities have the same importance.

The aforementioned concept of institutional hierarchy allows the analysis to incorporate the possibility that major institutional changes can take place without doubts being raised as to whether the institutional complementarity concept constitutes a sound basis for the varieties of capitalism or SSIP approaches. This hierarchy concept can be understood in two different ways. The first, which is discussed above, concerns the manner in which the institutional arrangements are conceived of - with a notion of hierarchy becoming obligatory when specific institutions incorporate into their own cognitive framework constraints and incentives that are associated with another institution. For Soskice [1999], the co-ordination between labour and employer unions lies at the summit of the institutional hierarchy, especially in Germany (with the government and the central bank in second place). For Aoki [2000], it is the interrelationship between banks, firms and the employment relationship that is the cornerstone of the Japanese system.

This definition of institutional hierarchy may be difficult to apply in practice if the reciprocal interactions that exist between the various institutional arrangements create an ambiguity with respect to the way in which the various constraints that the institutions are levying on one another can be interpreted. The definition of complementarities and of institutional hierarchies can therefore be extended with a dynamic perspective - and the transformation of a particular institutional complementarity (i.e., the reformulation [following a bout of financial deregulation] of the central role of bank funding of industry, or else a significant modification of forms of competition) can trigger the transformation of other complementarities by raising doubts as to the structure of a given institutional configuration, thus forcing transformations upon all of the institutions involved. It is to these types of upheavals that most analyses of modern economies are referring when they discuss the influence of globalisation or of the new economy ${ }^{29}$. By subjecting all countries to new and shared constraints, these phenomena raise questions regarding the institutional structures. They affect certain countries more than they do others - and they may ultimately cause countries to adopt one and the same model. We can identify historical trends towards homogenisation (i.e., the Americanisation of the Western economies during the post-war period) - but we can also find examples of the opposite trend.

The dynamics that have been driving the capitalist economies stem from the opposition between homogenisation tendencies and the trend towards the survival of national or regional particularities. Diversity is viable if this makes it possible to obtain growth rates that are comparable (if not exactly the same) between one country and

\footnotetext{
${ }^{28}$ More over hybridation can also be a first step in a process of radical change.

${ }^{29}$ Such a dynamic approach of hierarchy among sub sets of institutions, defined as structural forms of a growth regime, is developed in Petit (1999).
} 
another ${ }^{30}$ - whereas a configuration featuring a single model is not necessarily a stable one, if only because of the implications in terms of comparative advantage. Indeed, if one believes that institutions influence the economies' various industrial specialisations even more than their rates of growth, it is only possible to exploit divergences (one of the strongest foundations of international trade) if a modicum of diversity is maintained.

Which types of transformations affect all models of capitalism ? At a technological level, modifications can be expected to exist upstream from the relationships that exist between the development of sciences and their applications to innovation. Techniques and processes seem to be implementing generic, moveable and decontextualised knowledge in an increasingly direct manner - a knowledge that is likely to have a multitude of applications in a wide variety of fields. At a figurative level, this is something akin to the reacquaintance of innovation with strictly scientific fields. ${ }^{31}$ Moreover, this furthering of the types of knowledge that are being directly mobilised in innovation practices coincides with the transformation of a given science's own production regimes, which are more influenced by industrial problems - even if this takes the science away its traditional academic areas of scientific validation. ${ }^{32}$ Again at a figurative level, this second trend is somewhat akin to the scientific quest's descending into its fields of application. The development of this interface implies a whole set of relationships that lie at the very heart of the modern phase of internationalisation. This involves academic networks; information networks; and complex corporate service networks relating to companies who developed their internationalisation in the postwar era, first as a follow-up to the multinationals' overseas productive investments and subsequently (and for more or less 20 years now) as a standalone initiative.

Directly tied into this interface between science and technology is a whole new dynamic involving an inter-firm division of labour that reflects both a process of specialisation according to competencies and a lowering of transaction costs that have resulted from the diffusion of the new information and communications technologies. Other causes are the rise in agents' level of education and information - and internationalisation itself, construed here as an extension of the relational and strategic fields that are associated with the two other structural transformations. The most noteworthy aspect of this shift relates to the development of externalisation, with everything that this implies in terms of a tighter co-ordination of subcontracting and the use of companies that are involved in different types of business for those tasks where said companies are recognised as being the most competent. This increased competency is perceptible on two levels. Economies of scale remain an important factor, but it is principally from the so-called economies of scope that the new trend derives its capacity for an original type of success a characteristic of the period is that these economies of scope do occur more than in the past through the division of labour between firms, even of different sectors. This notion of economies of scope infers that the new division of labour is a bearer of learning processes which feature a greater potential for innovation. Of course, this covers all sorts of considerations, including the ability to engender product innovation, qualitative improvements, products and processes, as well as opportunistic methods for overcoming those elements that are seen as being a constraint on the principal order giver's employment relationship. Yet the new significance of this search for economies of scope also make it possible to transcend simple externalisation processes. It does this by encouraging the appearance of new tasks and new

\footnotetext{
${ }^{30}$ Switzerland and the United States followed the same growth trajectory between 1870 and 1990 , despite clearcut differences in their respective institutional architectures. The same thing could be said about France and Germany.

${ }^{31}$ Veltz [2000].

${ }^{32}$ As emphasised in a study by Gibbons et.al. [1994].
} 
professions best exemplified by the expansion of companies' tertiary activities (i.e., the significant rise of the service sector over the past 20 years). Figure 1 tries to recapitulate the various aspects of this flood of the modern inter-firm division of labour.

This environment has encouraged a rather peculiar management of innovation activities, with small firms (the start-ups) having been created to deal with given innovation projects. These firms assume project launch risks by relying on new systems of venture capital funding, and by opening their capital up, in the long run and if they are successful, to other investors (involving either a financial marketbased funding or else investments by the main companies that are already active in the branch). Hence the current interest in various forms of venture capital that in most developed economies will bear witness to the way in which such economies have been able to adjust to the new methods of innovation risk management - even if the proportion of total investment that has been funded by this sort of venture capital has ultimately remained very low (representing $0.2 \%$ of all investments in Europe in 1998). However, this does signify the existence of a logic wherein small firms in most European countries (those that have fewer than 50 employees) in both the manufacturing and service sectors have product or process innovation rates of between 40 and $60 \% .{ }^{33}$ Depending on the country, these innovation-geared small firms (not to be confused with small innovative firms, a standard categorisation that stresses these "traditional" small units' innovation capacities) have experienced varying trends. Some of them have succeeded in maintaining control over their development (one notorious example being Microsoft). Other innovative firms have in the medium run been reintegrated back into "traditional" large companies. It is not possible to decide which is preferable without first taking a broader overall view of the process. $^{34}$

Contemporary transformations imply that a newly intensive demand has been affecting the way in which the innovation processes are being shaped. This trend is part of a logic in which levels of competitiveness are being raised on all product and service markets, leading to greater attention being paid to "market demand". However, the usefulness of this trend stems precisely from the configuration(s) into which it translates as regards new arrangements and organisations - and not only from the greater attention that companies have been paying to certain factors.

All of these trends in the inter-firm division of labour (and in the markets' functioning) have ended up modifying the sources of information, and the systems for mobilising the types of knowledge that make up these innovation processes. This has had a profound effect on the economics of research and development. Here it is interesting to note that the ways in which the aforementioned adjustment of innovation processes is being concretised clearly vary from one country to the next yet they also present, depending on the circumstances, characteristics that are relatively similar in each of the countries. The European Community's 1996 innovation survey of companies revealed relatively similar structures as regards the sources of innovation-related information that the firms were declaring (whether it was suppliers, customers, fairs and exhibitions, specialised press,...). This similarity is a rough one at best, however an analysis of the levels of magnitude in the various countries reveals barely any "major structural" differences. We can view this similarity as one of the outcomes of the universality of this current institutional transformation. Of course, this does not preclude a survival of national specificities, such as those that can be found in the forms that have actually been adopted by these information

\footnotetext{
${ }^{33}$ According to Eurostat data compiled by the OECD in 1999 (table 11.4]. Note in addition that France is one of the few European countries (along with Belgium, Finland and Spain) where rates are below this $40 \%$ mark.

${ }^{34}$ See Amable, Breton \& Ragot [2001].
} 
processes. Nor does it preclude the efficient utilisation of these sources. Both are phenomena that infer the existence of complementarities; a reliance on other forms; and an impact on them.

\section{How to explain the divergences in performance during the $1990 \mathrm{~s}$}

Before analysing the SSIP's that were witnessed during the 1990s, we should verify whether the most frequent hypotheses concerning contemporary economic transformations can explain the differences in the developed economies' recent performances. The 1990s were characterised by large variations in this respect: strong growth in United States, an extended recession in Japan, recession and then recovery in Europe. One simple explanation for these variations could be summarised as follows : the nature of technical change has been modified, and as neo-Schumpeterian economists have foreseen ${ }^{35}$, a new technological revolution is in effect, one that could drive a new phase of growth. One of the technological features of this new economy, and ostensibly a driver of productivity gains, is the new information and communication technologies (ICT). These sectors play a double role. On one hand, they are an arena for the highest level of technical progress, with productivity gains that are significantly above gains in other sectors. They also feature a very high rate of product innovation. On the other hand, thanks to their diffusion throughout the whole economy, they enable other sectors to improve their own productivity, and to modify their offer in such a way as to encourage innovation. As such, information technologies play a role in their production as well as in their diffusion.

As a result, we can expect that those countries that have experienced a rapid diffusion of ICT, or who have been involved in a significant production of ICT, will be ahead of the other countries, at least during the ascending phase of a long-term cycle. It will be easier to understand this ascending phase insofar as its institutional conditions facilitate innovative dynamism. In particular, these conditions relate to the flexibility of the labour market, and above all to the dynamism of the financial markets : the availability of venture capital, the possibility that corporate executives can be incentivised through the attribution of stock options, the liquidity of the financial markets, etc. Market-based finance can be synthesised in one indicator - the price index of listed securities. In this view, the stock markets' dynamism can be crystallised as the changes in this indicator.

Another argument is closer to traditional macroeconomics and stresses that the developed countries did not all experience the same macroeconomic conditions over the course of the decade - if only because of the diversity of the macroeconomic policies that were being pursued (monetary policies in particular). The European recession of the early 1990s is not in fact unrelated to the restrictive monetary policies that were being carried out in light of the upcoming economic and monetary union.

Is it possible to explain international variations in macroeconomic performance on the basis of the aforementioned elements? Below we test two types of equations, one that explains GDP growth rates in volume terms, and another that looks at standardised unemployment rates. The sample comprises the performances of 10 OECD countries over the period 1991-2000: Canada, Denmark, Finland, France, Germany, Italy, Japan, the Netherlands, the United Kingdom, and the United States. As aforementioned, the explanatory variables will be ICT ; the stock market; and monetary policy. ICT will encompass two separate variables : (i) the proportion

\footnotetext{
${ }^{35}$ See Freeman \& Soete [1997]. We should remember that neo-Schumpeterians had been announcing the advent of an ICT-related technological revolution since the mid-1980s at least.
} 
of total GDP that was accounted for by the ICT producing sectors, and (ii) the same figures for ICT using sectors. Data on ICT producing and using sectors is drawn from the ICT database of the Groningen Growth and Development Center (University of Groningen, the Netherlands). We have no problems in interpreting the proportion accounted for by the ICT producing sectors, as this relates to the comparative importance of activities that are directly related to ICT. The ICT using sectors' proportion of total GDP replaces a variable that relates to the diffusion of such technologies. This is because of the well-known fact that capital goods diffusion variables are difficult to obtain for a whole economy over a period of several years and because such variables are not particularly reliable. However, the proportion of total GDP that is accounted for by the main ICT using sectors does not tell us anything a priori about the actual diffusion of these capital goods. The other explanatory variables are the real interest rate (measuring the restrictive nature of the monetary policy) and the stock index growth rate for that particular country.

Our findings are given in the appendix. Growth rate regressions are presented first. The initial model, with its fixed effects, only comes up with one single variable that is significantly associated with growth rates - the proportion accounted for by the ICT producing sectors. But conversely and strangely the utilisation of these technologies does not seem to have had any significant influence, and in fact, the estimated coefficient is negative ! Moreover, neither monetary policy nor stock market developments seem to have any apparent influence on growth. Note that the fixed effects are significant, indicating noticeable differences between the various countries' growth trends. This would tend to vindicate the idea that each is following a separate growth model. A random effect model presents parameters that are more interesting to interpret. The two variables that represent the importance of ICT (production and utilisation) have a significantly positive effect on growth. Note also the significantly positive effect of stock market developments, and the significantly negative impact of restrictive monetary policies. This would seem to be an ideal model for summarising the recipe for strong growth during the 1990s: technology (ICT), deregulated financial markets and a accommodative monetary policy. Unfortunately, different tests (i.e. Breusch-Pagan and Hausman) reveal a specification problem that forces us to return to a fixed effect model whose only clear conclusion is that the countries were indeed following different growth models (something that the [extremely mediocre] findings of the random coefficient model confirm). ${ }^{36}$ It also indicates that ICT production is probably a helpful phenomenon. In general, the introduction of additional variables did not enable a satisfactory level of specification. Findings were not only unsatisfactory - they were also fragile.

Findings from the unemployment rate test were slightly more explicit. The random effects model is satisfactory in specification testing terms. A significantly positive effect on growth rates can be observed. This is to say that once an adjustment has been made for the other effects, rapid growth leads to high unemployment. This very counter-intuitive possibility that growth may have a positive impact on unemployment finds some substantiation in theoretical literature ${ }^{37}$. Growth is based on innovation that possesses both creative and destructive elements. Innovation creates new jobs but destroys others, and a priori the net balance between the two is uncertain. Delocalisation of jobs can occur in the process as well as labour market mismatches, fired workers being unfit for the newly created jobs. Test findings would seem to indicate that the destructive aspect is the more significant of the two, in line with the process of "schöpferische Zerstörung" that was so characteristic of the 1990s. By itself, ICT would appear to have had a positive effect on employment. The utilisation, and above all the production, of information

\footnotetext{
${ }^{36}$ These findings are only presented for informational purposes. The model is difficult to estimate given the small number of observations that were made over time.

${ }^{37}$ See Aghion \& Howitt [1998: chapter 4].
} 
technologies helped to lower unemployment. Stock market developments did not have any significant effect and this variable is omitted from the findings being presented. Monetary policy had the anticipated effect, with a $1 \%$ rise in real interest rate leading to increase of $0.2 \%$ in unemployment. The mediocre findings of the random coefficient model are only shown for informational purposes. They indicate that the countries are probably pursuing different models that are difficult to identify due to the shortness of the period in question.

As the unemployment equation is more robust than the growth equation, we can pursue these estimations by integrating other variables that might account for the economies' competitiveness. The Lehman Brothers study referred to above offers a set of competitiveness indicators that come in the form of marks given to each country in areas such as education and training, technology, employment policies, etc. These variables are combined into three groups: those that concern the potential for growth ; those that relate to the labour market; and those that affect prices. Technology and the potential for growth were already dealt with in our estimations, through the integration of ICT production and utilisation variables. It is therefore the two other areas that interest us. We choose one variable in each area : employment protection ; and competition. Each of these variables is a composite that is determined from 15 to 20 indicators $^{38}$. Inasmuch as these are marks, the highest scores that each variable can receive corresponds to the situation that, from Lehman Brothers' point of view, is the most desirable one. Job protection is a bad thing (because flexibility needs to be increased, etc.), and therefore a high score for this variable corresponds to a low level of job protection. Competition is a good thing (so that margins can be lowered, leading to innovation, etc.), hence a high score for this variable corresponds to a high level of competition on the markets for goods and services. These variables are not available as time series. A single score is provided for each country.

Integrating these variables into the random effects model improves the regression. The two variables make a significant contribution to the model. As the traditional viewpoint would have it, job protection, such as it is apprehended in the variable that Lehman Brothers have devised, contributes to an increase in unemployment. According to the estimated scores, shifting from the level of protection that is characteristic of the Eurozone to a lower level of job protection would engender, everything else being equal, a reduction of $9.75 \%$ in the unemployment rate ! The effect of competition is less straightforward. Greater competition increases unemployment - an effect that can be justified theoretically ${ }^{39}$, seeing as greater competition renders firms fragile and forces them to make greater downwards adjustments in their staffing levels whenever, for example, an adverse demand shock occurs. In certain labour market imperfection configurations (relating for example to the search for efficient salary levels), job insecurity for employees can lead to higher real salaries, which can ultimately harm employment. This would seem to be the configuration that applies to the countries in our sample. If we were to continue to use the estimated scores, shifting from the levels of competition that are characteristic of the Eurozone to the ones that are prevalent in the United States would imply an increase of a $8.6 \%$ in the unemployment rate!

If institutional complementarities do indeed exist, this means that it would be difficult to adopt the institutional characteristics of United States' labour market whilst

\footnotetext{
${ }^{38}$ See Edwards \& Schanz [2001b]. The job protection indicator is built out of indicators such as the notice period before dismissal, the size of the settlement, the length of the probation period, the maximum number of times a fixed term contracts can be renewed, labour union rights, etc. The competition variable integrates elements such as sectorial concentration indices, the restrictiveness of competition-related legislation, the extent of competition from abroad, trade barriers, etc.

${ }^{39}$ See Amable \& Gatti [2000], [2001]
} 
maintaining the product and service market competition levels that are characteristic of the Eurozone. The good functioning of the labour market in the United States is based on a certain type of competition in the market for goods. Returning to an argument that is discussed above, it is not possible to adopt only one part of a given model's institutional structure - particularly if this is an essential part. Shifting to an American model (as regards levels of job protection and of competition) would therefore only lead to a lowering of $1.15 \%$ in the unemployment rate - nothing to be sneered at, of course, but this does not necessarily represent an increase in welfare for those economic agents who are worried about the level of risks that would result from increased job insecurity.

The regressions that are being presented here do not purport to account for everything. The findings are fragile, as indicated by the specification tests. They point towards the models ' heterogeneity, which is difficult to account for given the shortness of the period being studied. In other words the variety of the patterns of evolution prevents to identify one best way into the new growth regime. On the other hand, the findings do seem to provide one clear indication, which is that it is difficult to say whether the key to macroeconomic success resides in pursuing an American model in the shape of the new economy, involving deregulation and an accommodative monetary policy - that is, unless we naively consider that the best model simply corresponds to whichever economy has the highest growth rate at a given moment in time.

\section{The impact of internationalisation on the SSIPs' dynamics}

Did the main SSIP types as identified in Amable, Barré and Boyer [1997) change over the course of the 1990s ? More to the point, were there any modifications in the way in which the countries were grouped into four configurations/ideal-types ? Given the extent of the changes that took place in the general environment, one could expect internationalisation to have caused some change in findings from previous analyses (especially in light of the apparent move towards dynamics such as those that were underlying the US-driven market-based SSIP). We have carried out new empirical analyses to study these questions, trying to ascertain whether recent changes in the SSIPs have caused developed countries to remain part of the four main model categories mentioned above - or whether a number of shifts have in fact taken place (i.e., convergence towards a market-based SSIP).

These new empirical analyses are comparable to those found in Amable, Barré and Boyer [1997), but they do diverge on certain points. They involve recent data (the latest covers the latter half of the 1990s, the oldest the year 1995). They also cover more countries, 21 instead of 12: the United States, Japan, the United Kingdom, Canada, Australia, Italy, Spain, Portugal, Greece, France, Belgium, Denmark, Norway, Sweden, Finland, Germany, Austria, Switzerland, the Netherlands, Ireland, and Korea. We have kept the earlier study's system for breaking the SSIPs down into the various subsystems.

We try at first to identify the countries' groupings by only considering empirical data that relates to scientific and technological fields, economic structure, the educational system and the labour market. As such, this is an extended innovation system conception. However, we also start out by excluding variables pertaining to fields that are directly related to internationalisation, such as data on foreign trade or direct investment. We also exclude data that is related to the financial domain. Such data covers subsystems that might modify the SSIPS, and will be examined separately. 
Findings from our initial analyses are comparable to those obtained using data from the 1980s. We first consider the general typology, and achieve this by integrating all of the variables. We then take a closer look at the way in which the groupings mesh with the various subsystems. To the four SSIPs found in Amable, Barré and Boyer [1997), we add six country groups that are similar to the initial typology. The groups are as follows:

- A group comprising those countries that best embody the market-based SSIP including former members of this SSIP (United States, Great Britain, Canada Australia), joined by Norway which has some similarities with Canada and Austalia.

- A group comprising those countries that embody the social-democratic SSIP. The list includes the former countries from this SSIP (Finland, Sweden, Denmark), minus Norway.

- The mesocorporatist SSIP, with Korea and Japan.

- The "European integration" (or "public") SSIP, made up of most of the countries that already belonged to this SSIP (France, Germany, the Netherlands), now including Belgium and Ireland.

- An "Alpine" variant of the preceding SSIP, comprising Austria and Switzerland.

- A "Mediterranean" variant of the European SSIP, comprising Spain, Italy, Greece and Portugal.

Initial findings for the aforementioned variables show that some of the groupings that had been identified in the earlier study have survived. Certain groups have had to be reshuffled, with Norway drawing closer to the Anglo-Saxon countries, but the most noteworthy result involves the differentiation of the European SSIP into three variants.

The first issue that needs to be addressed involves the SSIPs' putative convergence towards a market-based model. Except for Norway, neither the countries' groupings nor the economic variables that distinguish the SSIPs from one another indicate any signs of a generalised convergence towards a market-based SSIP. Globally, each SSIP maintains its own distinctive features. However, subsystem analysis does not show that the SSIPs have remained unchanged. Quite the contrary, it provides glimpses of a deeper infiltration of certain market-based mechanisms in most economies. This advance of market-based mechanisms is localised in a finite number of subsystems ${ }^{40}$ and is concretised by the progressive transformation of the SSIPs (such as they are currently shaped) rather than by any radical transformation. This is one of the conclusions from Amable, Barré and Boyer [1997) that has been reinforced by these analyses of the SSIPs' recent changes. We should also mention traits that are common to all of the SSIPs: increased spending on $R \& D$, on research activities in general, and on economic activity in biology or ITrelated sectors. This general trend in the SSIPs, although it may vary for each of the countries concerned, reflects the advent of the new economy.

The European SSIP's heterogeneity, as already stated in Amable, Barré and Boyer [1997), is noteworthy for its breakdown into three variants. The first is a core group where France and Germany are the pivotal countries. The two other variants differ from the central group in terms of their average income levels, which are higher for the Continental variant, and lower for the "Mediterranean" one. This latter group is also characterised by its economies' lesser degree of technological intensity. But even this differentiation into three subgroups does not lead to particularly homogeneous groupings.

\footnotetext{
${ }^{40}$ Above all, in everything that pertains to the financial systems, and more generally, to the mobility of capital (see below).
} 
Table 4.1. summarises these analyses and allows comparisons to be made between those areas where countries belonging to one and the same SSIP act more or less similarly. It also makes it possible to compare the various SSIPs amongst themselves. The table can be read as follows: each line represents a subsystem or group of subsystems. The typologies that result from our data analysis translate into each country's receiving a number that represents the group to which it belongs (with respect to the particular data being analysed). The first line of the table represents all of the subsystems, ranging from scientific specialisation to education. The typology that comes out of this analysis leads to the six aforementioned country groups. The second line indicates the analysis's findings as regards scientific specialisation. The product of this analysis is a typology comprised of five country groups. The first group includes Australia and Great Britain (Group 1); the second the United States, Canada, Norway and Greece ${ }^{41}$, etc. This enables us to compare the finding of this subsystem analysis with the general analysis; and identify those subsystems where the countries belonging to a given SSIP are most similar to one another.

What we discover is that the market-based SSIP primarily groups countries that are similar in terms of their institutional variables : labour market; employment protection; employment structures; and educational system. The United States tends differs from Great Britain with respect to strictly technological or scientific variables. In simple terms, the "new economy" (in the technological sense of this expression at least) is not the only explanatory factor for the market-based SSIP.

Special attention should be paid to the factors that lead Norway to join this SSIP. The country's scientific specialisation is similar to Canada's and to the USA's and its number of publications is similar to this latter country's. On the other hand, in terms of its technological (e.g., patents) and industrial specialisation, it is closer to Australia or Canada (two countries that are highly endowed in natural resources) than to the United States or even Great Britain. Similarities can also be found on an institutional plane - the Norwegian labour market seems in certain respects closer to Anglo-Saxon flexibility, yet at the same time maintains some features that are characteristic of the social-democratic model, particularly as regards employment protection.

Some interesting information can also be drawn by analysing the results for the different variants of the "European" (or "public", for its continental variant at least) SSIP. The general impression from Table 4.1 is one of diversity. The reshuffled public SSIP (France, Germany, Belgium, Ireland, the Netherlands) is more or less homogeneous in terms of the way in which the State intervenes in the labour markets (except for the Netherlands); the employment protection (with Ireland continuing to be closer to the market-based SSIP); the relationships between employees and employers (except for France, which is closer to the Mediterranean variant); and the educational system (Ireland again being the exception). The other areas generally feature an opposition between the country groups that belong to this SSIP. France and Germany, for example, are close to one another in terms of their scientific specialisation, but not as regards their technological or industrial specialisation.

The Alpine variant of the European SSIP collates countries that resemble one another as regards a single subsystem - technological specialisation. In actual fact, although data analysis situates both countries within a single group, it does not really do justice to the deeper similarities that exist between them. In its "Mediterranean" variant, this SSIP combines countries that possess a number of shared characteristics in fields such as the labour market and, to a certain degree, scientific specialisation. However, it is difficult to distinguish any significant shared features,

\footnotetext{
${ }^{41}$ Greece is only included in this example for illustrative purposes.
} 
with the exception of their production systems' relatively lesser degree of technological intensity.

\section{Table 4.1 \\ Typologies of countries on the base of their productive structures and labour markets}

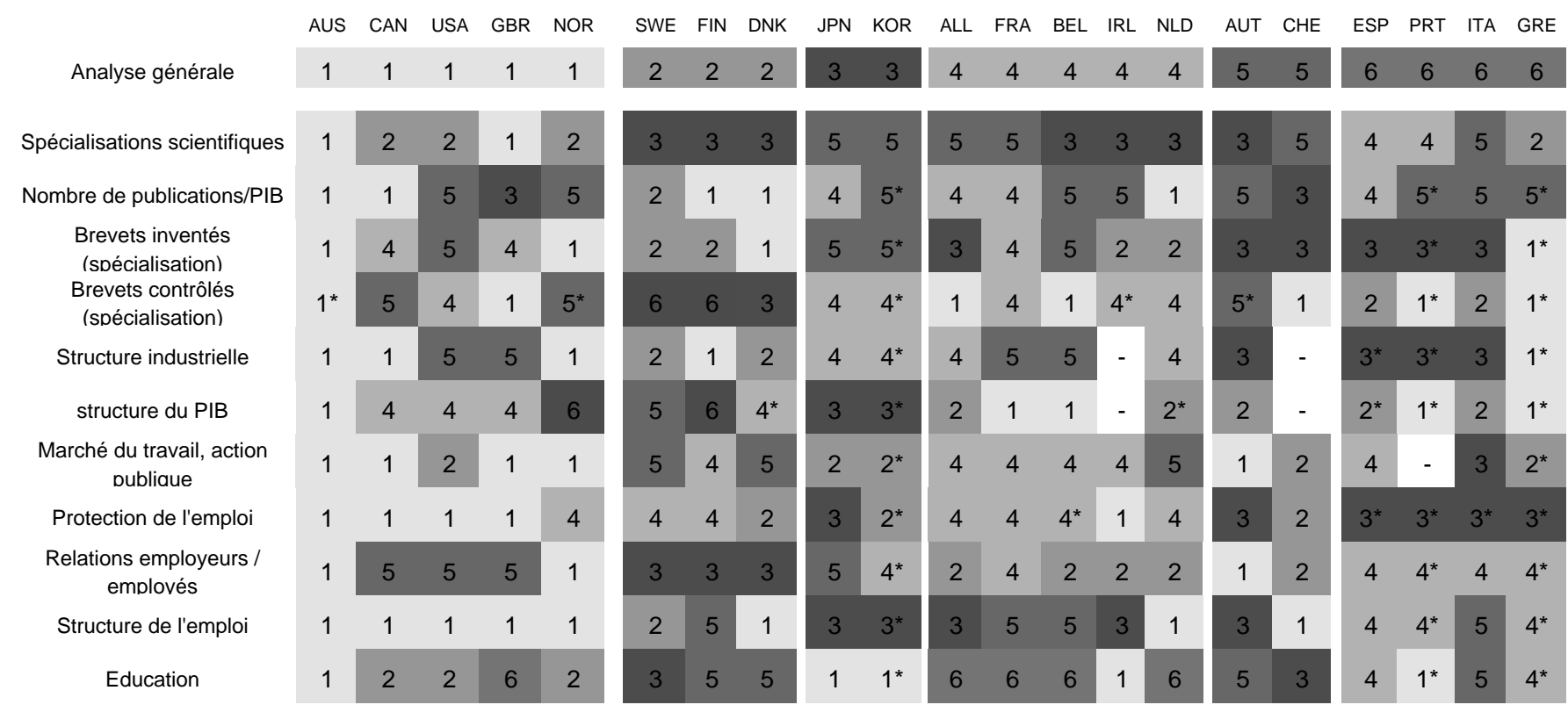

Notes : * illustrative countries

how to read the table : it reads by line, and gives the countries groupings corresponding to each line item. We thus have as many typologies as we have lines, except for the first line of general analysis which gives an overview (a synthesis) of all the typologies of the table.

To analyse the extent to which internationalisation affects the stability of these SSIPs, each of the variables that characterise this phenomenon have been processed separately. Whereas preceding analyses focused on the subsystems that lay at the very heart of the Nation-States' institutional organisation, recently there has been a move towards subsystems that are more open to international influences. These influences do not only involve the technology transfers (including all external effects that are related to the technology in question) that are presumably part of the trade in goods and services - they are also a reference to the mechanisms of "financial globalisation". This has had a big impact on national financial systems, leading in certain situations to major transformations that a priori will have an effect on each SSIP's innovation dynamics.

The results of these analyses are presented in Tables 4.2 and 4.3. They are laid out in the same form as in Table 4.1. For each Table, there is a general analysis covering all of the relevant subsystems, and providing a typology that is summarised in the first line of the Table.

Table 4.2 combines findings from the different analyses of the variables that stand for trade in goods and services; Table 4.3 presents analyses of the financial systems. 
The general analysis of internationalisation produces a country classification that is divided into five groups:

- A first group that matches the market-based SSIP

- The Mediterranean variant of the European SSIP

- A European SSIP subgroup plus Denmark

- Sweden and Finland twinned in one group

- A composite group: Austria, Japan, Germany, Ireland, Switzerland, and the Netherlands

The typology that is drawn from the scientific, technical and industrial subsystems which are featured in the preceding Table is only partially reproduced in other analyses - but certain country groupings crop up again and again, and make it easier to interpret these SSIPS. For example, the market-based SSIP seems to be remarkably coherent. Most of the countries that resemble this SSIP share certain traits in areas such as direct investment, outward-looking specialisations and financial systems. These countries are similar to the overseas investment specialisation model as regards their telecommunications, financial intermediation and primary goods. They import machines and metallic goods, and at least some of them are specialised in aeronautics. They also possess a number of shared characteristics with respect to their highly profitable banking sectors (which play a limited role in draining savings) and in terms of the role that institutional investors play in financing their economies and in re-allocating savings. ${ }^{42}$ Crossing variable in this way, we obtain a representation of some of the dynamics underlying the marketbased SSIP, including the specific dynamism of internationalisation, a trend that relies on an extension of market-based regulations (free movement of capital, financial deregulation, the dynamism of service activities) - a phenomenon that seems to coincide with a certain reduction in (localised) national industrial competitiveness.

Table 4.2

Typologies of countries on the basis of their external relations

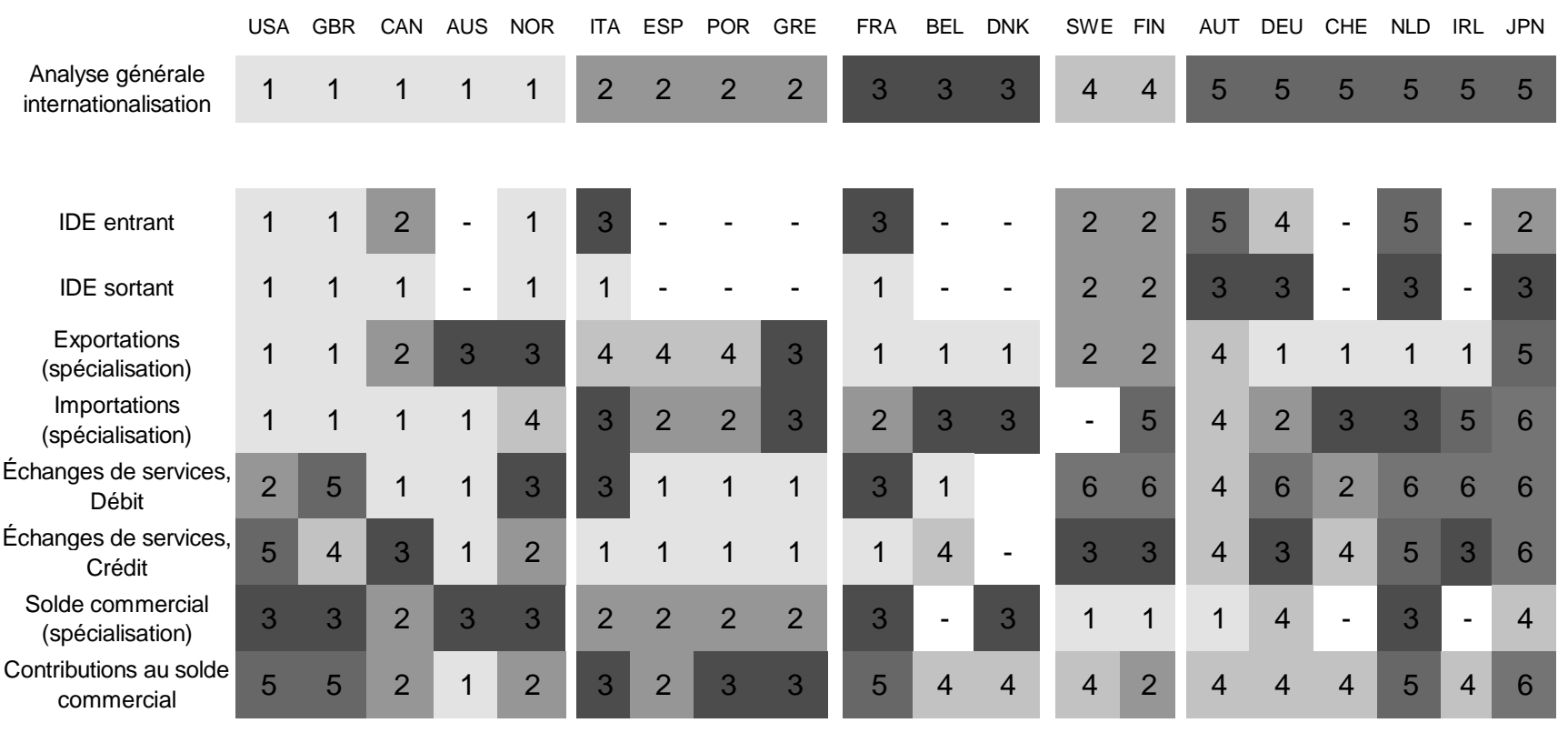

Note : how to read the table : see table 4.1

${ }^{42}$ See Paillard \& Amable [2000]. 
Note that the "Mediterranean" variant of the European SSIP is also in tune with this move towards internationalisation. However, given the available statistics, this result should not be granted the same significance as those findings that relate to the market-based SSIP. We can focus on the fact that the Southern European SSIP countries are similar in terms of their trade in services (if only because of the special role that tourism plays in their region); however they also possess shared characteristics pertaining to their financial systems, which are quite distant from the market-based finance model.

However, grouping countries by their internationalisation variables makes it possible to demonstrate the tensions that the other SSIP's are facing. These cross-SSIP groupings add a nuance to our previous conclusion, which was that the analyses presented in Table 4.1 indicate a relative stability. The main SSIP to be affected by this is the "European" or "public" one, which is already very heterogeneous. The countries encompassed in this SSIP are again combined into three different subgroups that mesh only partially with the previously observed combinations. More specifically, France and Germany are separated this time. A number of mechanisms help explain this "instability" of the European SSIP. The role of the international trade in goods is after all relatively limited. The differences that have been observed between the European countries are not any greater than those that are indicated in the analyses presented in Table 4.1. Here the differences between France and Germany are not enough in and of themselves to explain the split within the public SSIP. Even more significant are the differences which relate to the trade in services. These separate France from Germany, with the former being closer to Italy, and the latter closer to countries where the manufacturing sector plays a crucial role (Japan, Sweden, etc.)

Table 4.3

Typologies of countries on the basis of their financial structures

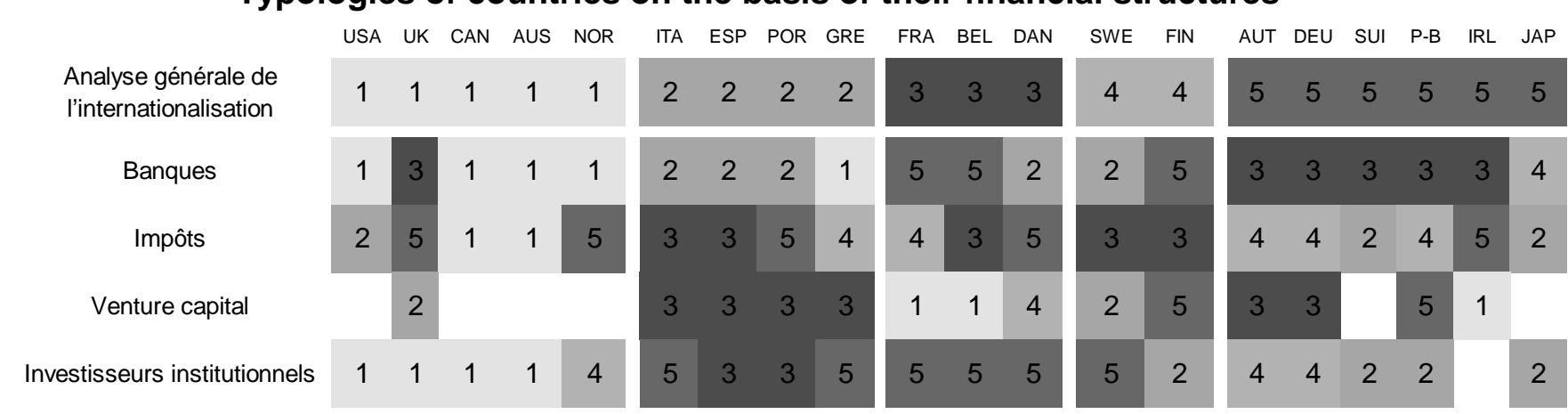

Note : how to read the table : see table 4.1

Changes in the financial system have also revealed varying levels of stability amongst the SSIPs. The market-based SSIP is remarkably coherent in terms of the way in which its national financial systems are configured, with banks playing a lesser role in corporate governance, and institutional investors (particularly pension funds) a greater one. There is nothing surprising about this description of the marketbased SSIP. Even more significant is the absence of any real convergence of the European SSIP towards a clearly defined model. The heterogeneity of the countries that make up this SSIP was furthered during the 1990s, at least in terms of their financial systems, with certain countries suffering from more or less serious bank crises, or at the very least, from lower levels of profitability (France, Belgium). This weakness of the bank sector kept such countries from playing the pivotal role that financial system economic theory ${ }^{43}$ attributes to them in terms of the control of investments, of industrial restructuring operations, etc.

\footnotetext{
${ }^{43}$ See Allen \& Gale [1999].
} 
The only real "bank-based" financial systems are found in Germany or Japan ${ }^{44}$, those countries that seem the least transformed by financial deregulation ${ }^{45}$ at least until the mid 90's. This is particularly true for Germany, whose relative stability should be compared with the transformations that have hit the French financial system, regarding sources of funding and corporate control ${ }^{46}$.

The differentiations between the various financial systems become particularly significant when we focus on venture capital ${ }^{47}$. This is a special way of funding investment projects; one that is different both from bank funding and also from market-based finance. It is similar to bank funding with respect to the specific way in which a project's development is monitored, and because of the significant involvement of the financial intermediary. It is complementary to market-based finance insofar as liquid and highly advanced financial markets enable the projects that are being developed with the help of venture capital to place their securities with the general public. As such, we can say that the development of a particular form of venture capital funding is compatible with both a bank-based and a market-based financial system.

In actual fact, analysis of the development and structure of venture capital in Europe (Amable, Paillard \& Petit, 1999) reveals that it would be overly simplistic to infer that venture capital is associated with market-based financial systems. Nor should we infer that to support this form of financing, an economy's funding systems have to be converted to Anglo-Saxon norms. Venture capital can assume several forms, as it can involve funding projects that feature varying degrees of innovativeness (with respect to their purely technological content). In general, venture capital can supplement current financial systems and develop according to its own original model whilst leveraging the strengths and weaknesses of the particular financial system.

Possibly even more important is the fact that if a significant amount of venture capital is to arise, a potential for innovation must exist. From this standpoint, certain countries can offset the alleged weakness of their financial systems by their strengths in research and technology. One only needs to take the example of Germany, where financial markets remain underdeveloped as regards their role in funding the economy, and above all, the control they exert over firms. As such, Germany would at first glance appear to possess very few advantages in this race to develop venture capital. Yet it is Europe's top country on this score, something that tends to prove that Anglo-Saxon type financial markets are not indispensable to the advance of venture capital. Even more important is the country's scientific and technological base, as well as the general adaptive capabilities of its financial system (whether "bank-based") $)^{48}$.

\section{Which institutional arrangements for the French/European SSIP?}

The diversity of the SSIPS is not only an academic issue - it also addresses problems relating to the definition of those structural policies that are most suited to a given situation. This aspect is especially fraught with consequences in the European

\footnotetext{
${ }_{44}^{44}$ Moreover, these two countries were far from identical with respect to their financial systems.

${ }^{45}$ A finding confirmed by more detailed analyses of financial systems in five countries (Hackenthal, 2000].

${ }^{46}$ Paillard \& Amable [2000].

${ }^{47}$ See Amable, Paillard \& Petit [1999].

${ }^{48}$ Boyer (2001) stresses that such synergy is even likely to be stronger in small countries as hinted at by the economic successes of Ireland and of the Scandinavian countries.
} 
countries, and in France in particular. Should European policies be differentiated to account for the diversity of the SSIPs that make up the European Union, or should they be uniform so as to respect a principle of equality, and in order to encourage a modicum of structural harmonisation?

As a geographic space, the EU encompasses 5 of the 6 possible SSIPs. In actual fact, the European SSIP, which covers the EU's largest countries, is the least homogeneous of the 6. As such, we could expect problems in defining "nondifferentiated" European policies in research and in technology, as well as in other economic domains. A similar argument in favour of heterogeneity has been made with respect to the definition of a common monetary policy in a space that comprises 11 (and one day 12) countries that differ greatly from many points of view ${ }^{49}$. This argument could mutatis mutandis be extended to cover industrial or research-related policies. How can countries belonging to innovation systems that are governed by sometimes radically different principles be made to advance in the same direction? One example is the opposition between Great Britain, which is close to the marketbased SSIP, and France. In the former, the research system (like the rest of the economy) is particularly responsive to any measure that emphasises financial incentives ; to rapid decision-making by the economic agents themselves ; in short and to simplify, to "flexibility". The French system on the other hand is characterised above all by the extent of the co-ordination between the various parties that are involved (research centres, firms, etc.), by the stability of relationships, etc. What is certain is that the definition of an industrial or research-related policy that revolves around market-based incentives and a principle of self-organising markets is a better match for countries belonging to the market-based SSIP than for members of the public SSIP - in other words, for Great Britain rather than for France.

The European SSIP's heterogeneity poses an additional problem. The countries that are close to this model are some of the EEC's founding nations, notably France and Germany. These two countries being the ones that provide the impetus for European construction in almost all areas, it would surely be very useful for them if they were to converge ultimately towards similar technology and growth policies. Their shared proximity to one and the same SSIP is a positive factor, but this SSIP's lack of homogeneity or "coherency" (the common elements that unite the countries comprising this SSIP are relatively few in number, tending to twin countries on a twoby-two basis) raises fears that the economies' internationalisation processes will lead to divergences. It would be inaccurate to interpret the principles of the European SSIP as a refusal of the principles of competitiveness instead of as an original model within which science and innovation rely to a large extent on public actions. The advent of venture capital in France and in Germany provides an illustration of differentiated adaptations. Changes in forms of competition have impelled the economies to develop funding modes that are able to assume a greater proportion of innovation-related risks. The various countries' response depends directly upon the characteristics of their SSIP. The rise of this type of funding in the United Kingdom is no surprise. Even more salient for our study is possibly the originality and success of a German approach that has been developing with great speed, largely based on that country's federal structure and on its traditional mechanisms of public governance.

The SSIPs' current changes are discernable in the fields of finance and technology. The first technological dimension can be observed through some of the specific changes being experienced by those countries that feature a high level of technological intensity, such as Finland or Sweden. Such countries are going through

\footnotetext{
${ }^{49}$ A similar plea for a differentiation of European structural policies can be found in Boyer, Dehove (2001)
} 
dynamics that are different from the changes occurring in countries that feature a lower level of technological intensity, such as those that make up the Mediterranean variant of the European SSIP. The two economies in the social-democratic SSIP are characterised by their production system's high level of technological intensity; by their international competitiveness; and by institutions that are very different from those that can be found in the market-based SSIP - despite the fact that this latter model is commonly depicted as being the only one capable of guiding countries into a "new economy". Although we should be cautious when comparing medium-sized countries such as France or Germany with small and very open economies such as Finland or Sweden, there is good reason to believe that the market-based SSIP path is not necessarily the only one that can explore a growth trajectory featuring a high level of scientific and technological intensity.

For the European SSIP to follow this path, the European Union countries would have to increase their average technological intensity. This scientific (and above all technological) leap forward is mainly achievable in countries with hi-tech activities, an extensive scientific and technical potential, and a highly developed industrial sector. It will therefore be a priority that France and Germany be the ones to assume responsibility for exploring the road towards a "new European economy".

To follow this trajectory, a significant hike in R\&D efforts is necessary, if only so as to match the relative levels of the United States, Japan, or the Scandinavian countries. Given the research structures' separation into national entities throughout the EU, we can even assume that in order to reach a given objective, EU countries should run the risk of duplicating research projects, and therefore incurring extra R\&D expenses. The United Kingdom appears to be benefiting form its de facto co-operation with the American system, and this helps it to remain a member of the market-based SSIP. Although the European public SSIP does not present the same internal coherency, it would appear that close co-operation, adapted to the specificities of the models of the countries involved (notably France and Germany), will enable such countries to maximise the benefits they draw from the efforts they are making in the technological field.

Lastly, some predict that the financial dimension (corporate governance above all) may well upset the European SSIP's stability. As we have already seen, financial deregulation and the increased role of the financial markets have not had the same consequences everywhere. More specifically, France is the country where the structures of the financial system have undergone the greatest changes ${ }^{50}$. In a country like Germany, where bank-based funding, industrial concentration and social partnerships have strengthened one another mutually, and defined an industrial model that Streeck [1991) calls "the differentiated production of quality", financial deregulation has been much more limited, and has not fundamentally altered the banks' role. Nor has it raised any doubts over the stakeholder capitalism that up until now has been the main feature of German capitalism. As such, this capitalism is not only based on a co-ordination of banks and industrials - it also revolves around coordinations between employees and firms, with each group being represented by powerful collective actors. Conversely, in a country like France that has never featured stakeholder capitalism, and which has therefore never had any negotiation or co-ordinating structures upon which this particular model could be based, the deep structural change that has been affecting the financial system and the mode of corporate governance carries changes that are more radical (with respect to the particular style of capitalism that is involved).

\footnotetext{
${ }^{50}$ For additional proof in this respect, see Goyer [2001], Hacketal [2000] or Schmidt [2001].
} 
Stakeholder capitalism does not only revolve around a bank-based financial system (or a financial system that encourages long term commitments). It also requires a wide variety of other institutions that can complement this type of corporate governance. It should therefore be more difficult to destabilise this model as a result of changes in one of the institutions, in light of the complementary relationships that exist with other institutions. This type of complementarity is not characteristic of France, which has never experienced stakeholder capitalism - if only because of the absence of the institutions that this model demands, basically meaning everything that reinforces negotiation and co-operation. Nor is France representative of shareholder capitalism, what with the role of the French State and the lesser development of the country's financial markets (until the 1990s at least). To simplify, in the French model, it is the State that is responsible for the co-ordination function. There are no intermediary compromise negotiation levels, as is the case in Germany for example. Given the absence of public intervention, and within the framework of a financial deregulation that is being orchestrated by state authorities themselves, many institutional complementarities might end up being overturned inasmuch as no stable compromise (as regards the institutional configuration) exists between the intermediary actors, as is the case in Germany. With the changes in its financial system, France may be the country in the European SSIP that is the more engaged into a shareholder capitalism. It is not at all clear that this hybridisation is the one that is best suited to the type of innovation that drives French competitiveness - meaning, and again to simplify, a type of project innovation that requires co-ordination between public actors and firms, as well as decisions that are made with a view to the long term future. 


\section{References}

Aghion P. and P. Howitt [1998] Growth Theory. Cambridge, Mass., MIT Press.

Albert M. [1991] Capitalisme contre capitalisme. Paris : Seuil

Amable B. [2000] Institutional complementarity and diversity of social systems of innovation and production. Review of International Political Economy 7:4, 645-687.

Amable B., R. Barré and R. Boyer [1997] Les systèmes d'innovation à l'ère de la globalisation. Economica, Paris.

Amable B., R. Breton and X. Ragot [2001] Does the 'new economy' change the frontiers of the large corporation? Mimeo CEPREMAP.

Amable B., Y. Cadiou and P. Petit [2000] On the Development Paths of Innovation Systems. Work Package D, TSER-CDIS Project, Mimeo CEPREMAP.

Amable B., E. Ernst and S. Palombarini [2000] Institutional Complementarity: labour markets and finance. Mimeo CEPREMAP

Amable B. and D. Gatti [2000] The impact of product market competition on employment and wages. Mimeo CEPREMAP-WZB

Amable B. and D. Gatti [2001] Product market competition and employment protection: a case for policy complementarity. Mimeo CEPREMAP-WZB

Amable B., S. Paillard and P. Petit (2000) Venturing on the Risk Frontier. Mimeo CEPREMAP

Amable B. and P. Petit [1999] Identifying the Structure of Institutions to Promote Innovation and Growth. Working Paper CEPREMAP no 9919.

Aoki M. [2000] Information, Corporate Governance, and Institutional Diversity. Oxford: Oxford University Press.

Aoki M. [2001] Towards a Comparative Institutional Analysis. Cambridge, Mass. MIT Press

Arthur B. [1994] Increasing Returns and Path Dependence in the Economy. Ann Arbor: University of Michigan Press.

Artus P. [2001] La nouvelle économie. Paris : La Découverte.

Beffa J.L., R. Boyer and J.P. Touffut [1999] Les relations salariales en France. Notes de la fondation Saint-Simon

Boyer R. [2001] La diversité des institutions d'une croissance tirée par l'information ou la connaissance in Institutions et Croissance, les chances d'un modèle économique européen. Colloque Centre Saint-Gobain, Touffut J.P. ed. Albin Michel, Paris.

Boyer R., Dehove M. [2001] «Du gouvernement économique » au gouvernement tout court, (en collaboration avec Mario Dehove), Critique internationale, n¹1, avril, p.179-195.

Brynjolfsson E and B. Kahin (Eds) [2000] Understanding the Digital Economy. Data, Tools and Research. Cambridge, Mass. MIT Press

Cadiou Y. [2001] Théorie des systèmes nationaux d'innovation: une analyse comparative de la France et du Japon dans la dynamique de mondialisation. Thèse de doctorat, Université Paris 7.

Coe D. and Snower D. [1997] Policy Complementarities: the case for fundamental labour market reform. CEPR Discussion Paper No.1585. 
David P. [1994] Why Are Institutions the Carriers of History ? Notes on PathDependence and the Evolution of Conventions, Organisations and Institutions. Structural Change and Economic Dynamics. Vol.5, 205-220.

Edwards J. and J. Schanz [2001a] Faster, higher, stronger. An international comparison of structural policies. Structural Economics Research Papers No 3 Lehman Brothers.

Edwards J. and J. Schanz [2001b] Lehman's structural database. Sources and methods. Structural Economics Research Papers No 4 Lehman Brothers.

Ernst E. [2001] Complémentarités institutionnelles et croissance économique à long terme. Thèse de doctorat, Ecole des Hautes Etudes en Sciences Sociales.

Freeman, C. [1987] Technology, policy, and economic performance : lessons from Japan. London ; New York, Pinter Publishers.

Freeman C. [1995] The National System of Innovation in Historical Perspective. Cambridge Journal of economics. 19(1), 5-24.

Freeman, C. and L. Soete [1997] The economics of industrial innovation. Cambridge, Mass., MIT Press.

Freeman R. [2000] Single-peaked vs. diversified capitalism: the relation between economic institutions and outcomes. NBER Working Paper.

Gatti D. [2000] Compétences, organisations et coordination dans une économie d'innovation. Thèse de doctorat, Ecole des Hautes Etudes en Sciences Sociales.

Gibbons, M. [1994] The new production of knowledge : the dynamics of science and research in contemporary societies. London ; Thousand Oaks, Calif., SAGE Publications.

Goyer M. [2001] Corporate governance and the innovation system in France: the development of firms' capabilities and strategies, 1985-2000. forthcoming Industry and Innovation.

Hackethal A. [2000] How Unique Are US Banks ? The Role of Banks in Five Major Financial Systems. Johann Wolfgang Goethe-Universität Fachbereich Wirtschaftswissenschaften No.60.

Jacquet P. and F. Sachwald [2000] Mondialisation: la vrai rupture du Xxe siècle. Politique Etrangère 3-4, 597-612.

Kitschelt H., Lange P., Marks G. and Stephens J.D. [1999] Convergence and Divergence in Advanced Capitalist Democracies. In H. Kitschelt, P. Lange, G. Marks and J.D. Stephens (Eds) Continuity and Change in Contemporary Capitalism. Cambridge: Cambridge University Press.

Kogut B. [2000] The Transatlantic Exchange of Ideas and Practices: National Institutions and Diffusion. Les notes de l'ifri $\mathrm{n}^{\circ} 26$.

North D. [1990] Institutions, Institutional Change and Economic Performance. Cambridge: Cambridge University Press.

OECD [1999] Tableau de bord de la science, de la technologie et de l'industrie, 1999 : Mesurer les économies fondées sur le savoir. Paris: OECD.

OECD [2000] A New Economy? The changing role of innovation and information technology in growth. Paris: OECD.

Orszag M. and Snower D. [1998] Anatomy of policy complementarities. CEPR Discussion Paper No. 1963. 
Paillard S. and B. Amable [2000] Intégration européenne et systèmes financiers : y at-il convergence vers le modèle anglo-saxon ? Mimeo CEPREMAP.

Petit P. (1999) "Structural Forms and Growth Regimes of the Post Fordist Era". Review of Social Economy, eptember

Schmidt R.H [2001] The Future of Banking in Europe. Johann Wolfgang GoetheUniversität Fachbereich Wirtschaftswissenschaften $N \times 72$.

Smith K. [1998] Innovation as a systemic phenomenon : Rethinking the role of policy. Contribution to The Innovation Systems and European Integration (ISE) Research Project.

Soskice D. [1999] Divergent Production Regimes: Coordinated and Uncoordinated Market Economies in the 1980s and 1990s. Dans Kitschelt H., P. Lange, G. Marks et J.D. Stephens (Eds) Continuity and Change in Contemporary Capitalism. Cambridge University Press.

Streeck W. [1991] On the Instritutional Conditions of Diversified Quality Productions. In E. Matzner and W. Streeck (eds) The Socioeconomics of Production and Development. London: Edward Elgar.

Théret B. [1997] Méthodologie des comparaisons internationals, approche de l'effet societal et de la regulation : fondements pour une lecture structuraliste des systèmes nationaux de protection sociale. L'Année de la régulation, vol.1 163-228.

Théret B. [2001] Changes in the French Social Protection System : Path Dependencies, Timing, and International Challenges. Mimeo.

Veltz P. [2000] Le nouveau monde industriel, Gallimard, Paris.

Whitley R. [2000] Divergent Capitalisms. The social structuring and change of business systems. Oxford: Oxford University Press. 


\section{Annexe}

\section{A1. Regression of the growth rate of real GDP on:}

- the share of ICT producing sectors in GDP (logs, lagged): lictpro1

- the share of ICT using sectors in GDP (logs, lagged): lictus1

- the real rate of interest: $\mathrm{nr}$

- the growth rate of the share price index: gb

\section{A.1.a Fixed effects model}

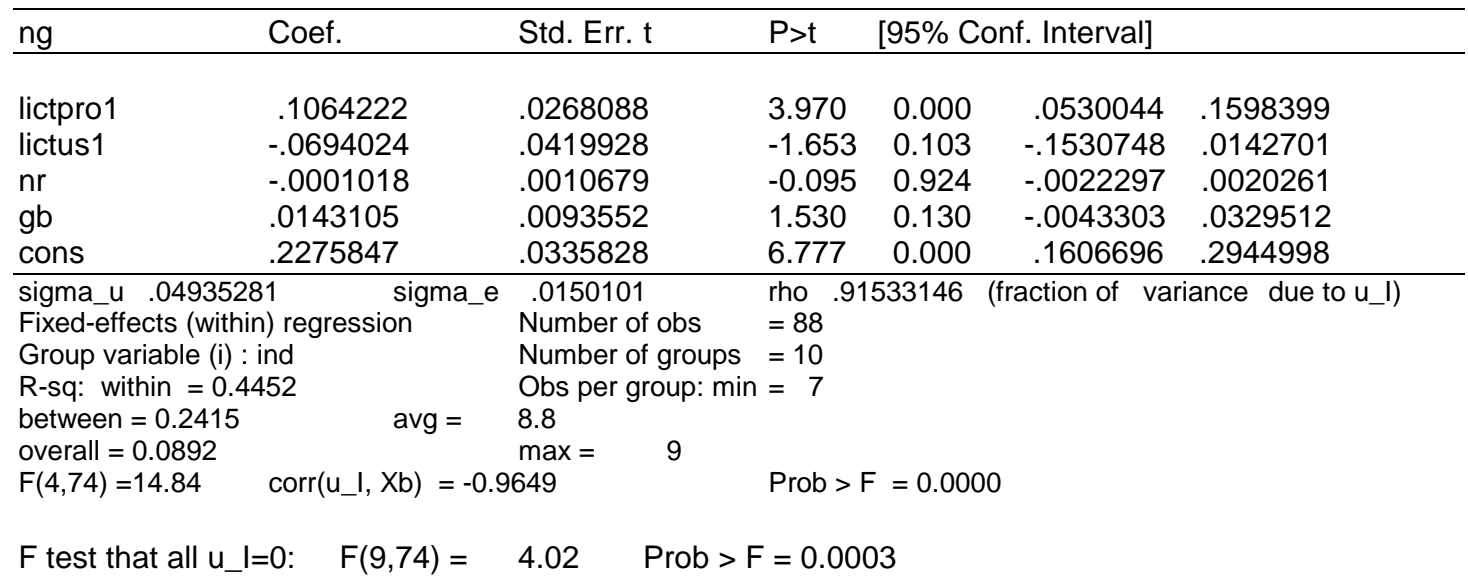

\section{A.1.b Random effects model}

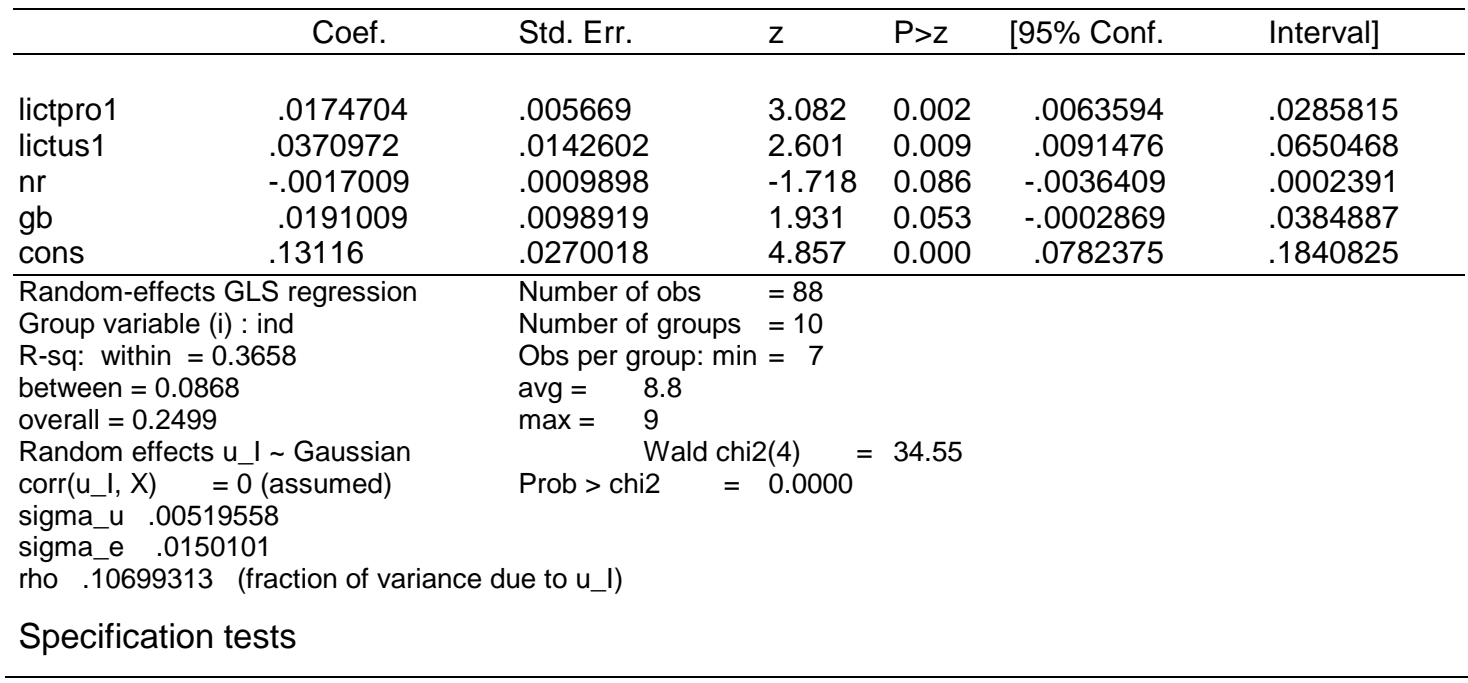

Breusch and Pagan Lagrangian multiplier test for random effects

$$
\operatorname{chi} 2(1)=1.57
$$$$
\text { Prob }>\text { chi2 }=0.2097
$$ 


\section{A.1.c Random coefficients model}

\begin{tabular}{lllllll}
\hline & Coef. & Std. Err. & $\mathrm{z}$ & \multicolumn{2}{l}{$\mathrm{P}>\mathrm{z}$} & \multicolumn{2}{l}{ [95\% Conf. Interval] } \\
\hline lictpro1 & -.1136897 & .1102501 & -1.031 & 0.302 & -.3297759 & .1023965 \\
lictus1 & .2098802 & .1599841 & 1.312 & 0.190 & -.1036829 & .5234433 \\
$\mathrm{nr}$ & .0004839 & .0030848 & 0.157 & 0.875 & -.0055622 & .00653 \\
gb & -.004341 & .0203438 & -0.213 & 0.831 & -.044214 & .0355321 \\
cons & -.0227405 & .1530632 & -0.149 & 0.882 & -.3227389 & .2772579 \\
\hline
\end{tabular}

Hildreth-Houck random-coefficients regression Number of obs $=88$

Group variable (i) : ind Number of groups $=10$

Obs per group: $\min =7$

$\operatorname{avg}=8.8$

$\max =9$

Wald chi2(4) $=2.55$

Prob $>$ chi $=0.6362$

Test of parameter constancy: $\quad$ chi2 $(45)=214.51 \quad$ Prob $>$ chi $2=0.0000$

\section{A2. Regression of the unemployment rate on:}

- the share of ICT producing sectors in GDP (logs, lagged): lictpro1

- the share of ICT using sectors in GDP (logs, lagged): lictus1

- the real rate of interest: $\mathrm{nr}$

- the growth rate of the share price index: gb

- $\quad$ the real GDP growth rate

\section{A.2.a Random effects model}



Breusch and Pagan Lagrangian multiplier test for random effects

Hausman specification test

$\operatorname{chi} 2(1)=109.51$

$\operatorname{chi} 2(4)=0.43$

Prob $>$ chi2 $=0.0000$

Prob $>$ chi2 $=0.9798$ 


\section{A.2.b Random coefficients model}



A.2.c random effects model with competition (compet) and employment protection (protec) variables

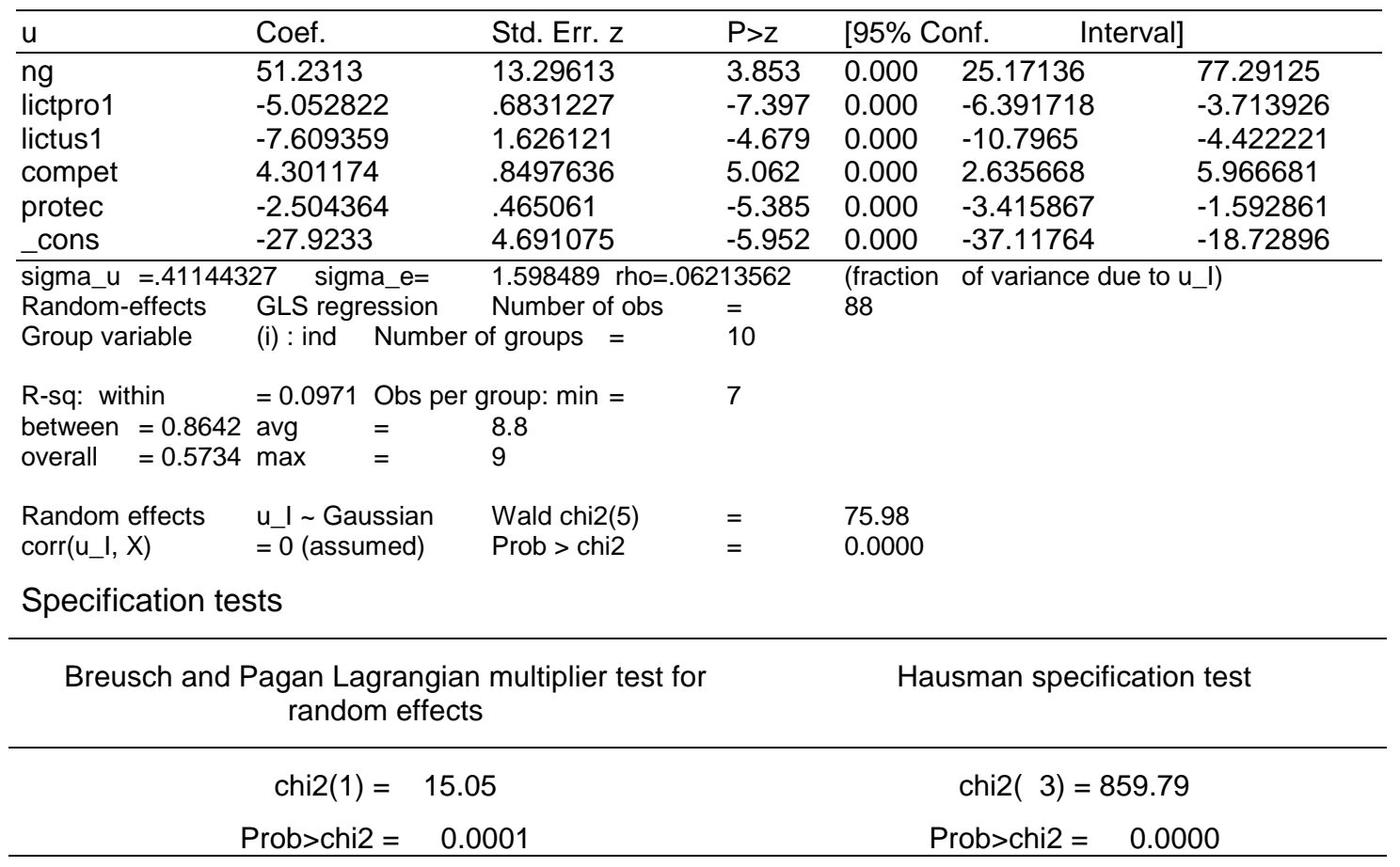


A.2.d GLS estimates with autocorrelation

\begin{tabular}{lllllll}
\hline $\mathrm{u}$ & Coef. & Std. Err. & $\mathrm{z}$ & $\mathrm{P}>\mathrm{z}$ & [95\% Conf. & Interval] \\
\hline ng & 21.67025 & 10.45241 & 2.073 & 0.038 & 1.18394 & 2.15659 \\
lictpro1 & -3.966477 & .7278157 & -5.450 & 0.000 & -5.392969 & -2.539984 \\
lictus1 & -5.432063 & 1.802261 & -3.014 & 0.003 & -8.964429 & -1.899696 \\
compet & 3.701801 & .9619093 & 3.848 & 0.000 & 1.816494 & 5.587109 \\
protec & -2.087879 & .521919 & -4.000 & 0.000 & -3.110822 & -1.064936 \\
cons & -20.15441 & 5.080466 & -3.967 & 0.000 & -30.11194 & -10.19688 \\
\hline
\end{tabular}

Cross-sectional time-series FGLS regression

Coefficients: generalized least squares

Panels: homoscedastic

Correlation: common AR(1) coefficient for

Estimated covariances $=1$

Estimated autocorrelations $=1$

Estimated coefficients =

Numb

all panels (0.5605)

Number of obs $=88$

Number of groups $=\quad 10$

avg $=8.840909$

$\max =9$

Wald chi2(5) $\quad=\quad 41.60$

Log likelihood $\quad=-118.8942$

Obs per group: $\min =\quad 7$

\section{A.2.d GLS estimates with panel-specific autocorrelation}

\begin{tabular}{lllllll}
\hline $\mathrm{u}$ & Coef. & Std. Err. & $\mathrm{z}$ & $\mathrm{P}>\mathrm{z}$ & [95\% Conf. & Interval] \\
\hline $\mathrm{ng}$ & 18.89844 & 9.8303 & 1.922 & 0.055 & -.3685911 & 38.16548 \\
lictpro1 & -3.626333 & .7478814 & -4.849 & 0.000 & -5.092153 & -2.160512 \\
lictus1 & -4.709533 & 1.771838 & -2.658 & 0.008 & -8.182271 & -1.236795 \\
compet & 3.237552 & .681753 & 4.749 & 0.000 & 1.901341 & 4.573763 \\
protec & -1.707845 & .4325217 & -3.949 & 0.000 & -2.555572 & -.8601183 \\
cons & -17.90701 & 4.628392 & -3.869 & 0.000 & -26.97849 & -8.835524 \\
\hline
\end{tabular}

Cross-sectional time-series FGLS regression

Coefficients: generalized least squares

Panels: homoscedastic

Correlation: panel-specific $\mathrm{AR}(1)$

Estimated covariances $=1$ Number of obs $=88$

$\begin{array}{lll}\text { Estimated autocorrelations }= & 10 \quad \text { Number of groups }= & 10\end{array}$

Estimated coefficients $=6 \quad$ Obs per group: $\min =\quad 7$

$\begin{array}{lll}\text { avg } & =8.840909\end{array}$

$\max =$

Wald chi2(5)

Log likelihood

$\begin{array}{ll}9 & 36.15\end{array}$

$=-110.6054 \quad \operatorname{Pr}>$ chi $2=0.0000$ 
FIGURE 1

The expansion of the inter firms division of labour

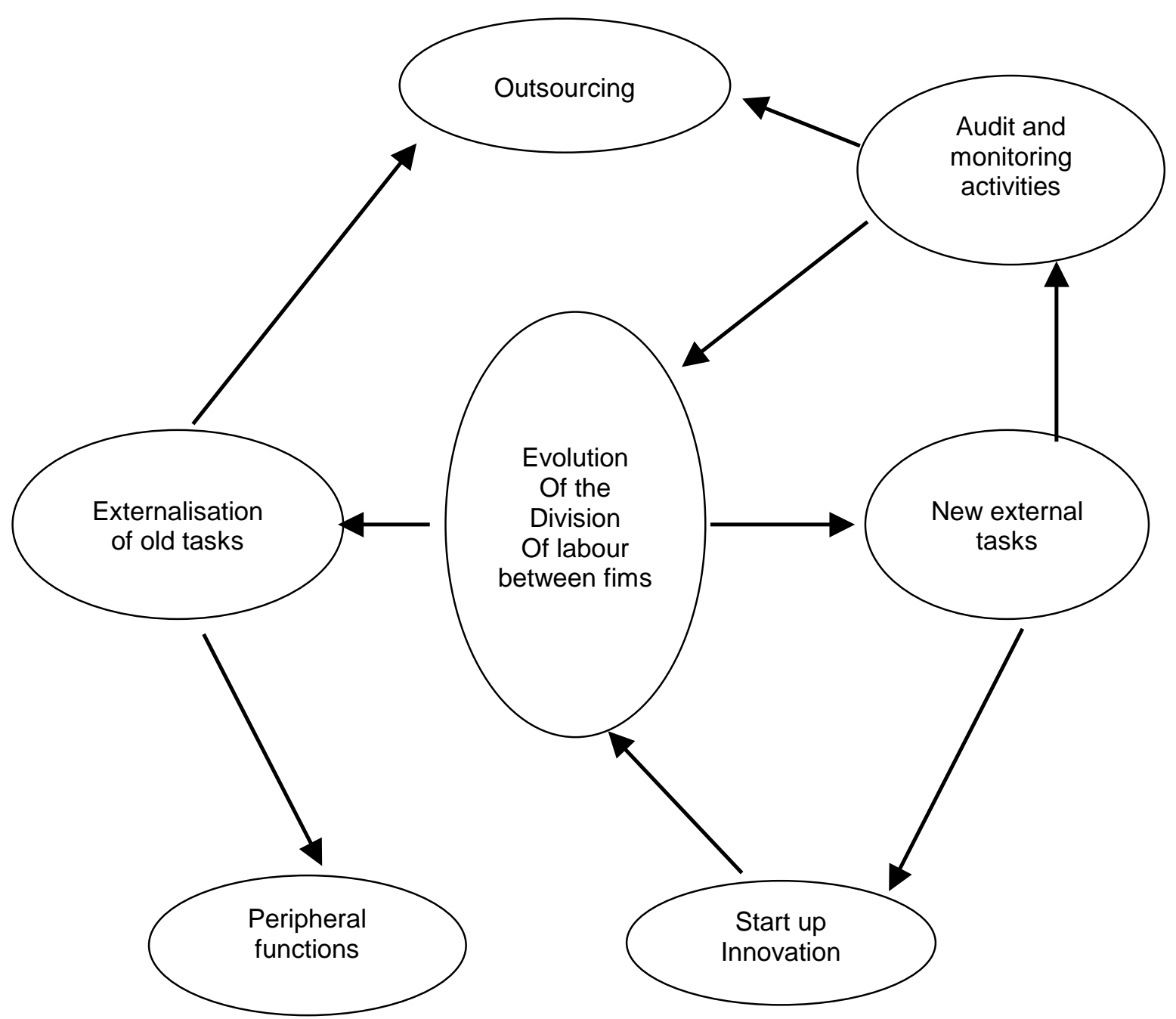

